\title{
Percepción social de las repercusiones paisajísticas de la urbanización dispersa en espacios rurales del entorno litoral mediterráneo
}

\author{
Social perception of the landscape effects of dispersed urbanisation \\ in Mediterranean coastal rural areas
}

\author{
Matías Mérida Rodríguez ${ }^{1^{*}}$ \\ María Jesús Perles Roselló ${ }^{2}$ (i) \\ Juan Francisco Sortino Barrionuevo ${ }^{3}$ (D) \\ David Carruana Herrera ${ }^{4}$ (1)
}

\section{Resumen}

Este trabajo se marca como objetivo analizar la percepción de las repercusiones paisajísticas de un fenómeno de gran trascendencia territorial en los entornos litorales mediterráneos: la urbanización dispersa en suelos rurales. Tras la caracterización de los principales rasgos de este proceso territorial y el análisis de la zona de estudio, la comarca de la Axarquía (Málaga), se expondrán los resultados obtenidos a partir de la realización de encuestas a diversos grupos de población residente en estos espacios y en las localidades cercanas, oponiendo particularmente la percepción de diferentes grupos de población local con la de la población extranjera afincada en estas áreas. Se abordará especialmente la percepción de los rasgos paisajísticos de la comarca y la valoración de los cambios producidos, directa o indirectamente, por la proliferación de edificaciones aisladas, profundizando en determinadas variables y componentes paisajísticos. Los resultados reflejan la existencia de una percepción paisajística relativamente sólida favorable a esta dinámica territorial, así como notables disparidades entre las valoraciones realizadas por los diversos grupos de población, especialmente entre los compuestos de población nacional.

Palabras clave: percepción del Paisaje; urbanización dispersa; litoral mediterráneo; población local; Axarquía; Málaga.

\begin{abstract}
This work analyses perception of the landscape effects of a phenomenon of great territorial importance in the Mediterranean region: dispersed urbanisation in rural areas. After the characterisation of the main features of this territorial process an analysis is made of the study area: the Axarquía region near Malaga in Spain. The results obtained from conducting surveys of various population groups residing in these spaces and in nearby localities is presented. A comparison is made of the perceptions of various groups of the local population with those of foreigners living in the area. The perception of the landscape features of the region and the assessment of the changes produced by the proliferation of isolated buildings is analysed, together with an evaluation of certain variables and landscape components. The results reflect

\footnotetext{
1 Departamento de Geografía, Universidad de Málaga, España. mmerida@uma.es. * Autor para correspondencia

2 Departamento de Geografía, Universidad de Málaga, España. miperles@uma.es

3 Departamento de Geografía, Universidad de Málaga, España. francis.sortino@uma.es

4 Departamento de Geografía, Universidad de Málaga, España. carruanadavid@gmail.com
} 
the existence of a favourable perception of this territorial dynamic, as well as notable disparities between the assessments made by the various population groups (especially among the national population).

Keywords: landscape perception; rural sprawl; Mediterranean area; local people; Axarquía; Málaga.

\section{Introducción}

La expansión de la urbanización dispersa en espacios rurales constituye un proceso territorial que ha experimentado un gran crecimiento en las últimas décadas en el entorno del litoral mediterráneo andaluz. A menudo desarrollada sobre suelos clasificados como no urbanizables, su proliferación ha producido importantes consecuencias urbanísticas, legales, medioambientales y paisajísticas. Ante el problema generado, la Administración autonómica ha impulsado diferentes medidas normativas tendentes a su regularización (Decreto 2/2012, Ley 6/2016, Ley 2/2018). Por ello, habitualmente este fenómeno es percibido de forma negativa, tanto desde el ámbito técnico como desde el político, trasladándose esta opinión al espacio mediático y, por extensión, al conjunto de la población. Por el lado contrario, únicamente asoman a los medios de comunicación la opinión de la población directamente interesada, los propietarios de estas edificaciones, pero habitualmente restringida solamente a los problemas de legalidad urbanística a los que se enfrentan. Sin embargo, más allá de su argumentación jurídica, existe un cierto desconocimiento de la percepción paisajística del fenómeno que tienen estos residentes, alimentado en buena medida por su condición de ciudadanos extranjeros, con dificultades de comunicación y ciertas diferencias culturales con la población local.

Por otra parte, en el análisis de este proceso territorial resulta poco conocida la percepción que tiene del mismo y de sus repercusiones paisajísticas la población local, la residente en el entorno de estas construcciones, a pesar de que, activa o pasivamente, se encuentra muy implicada en este fenómeno (además de formar puntualmente también parte de él), tanto por los beneficios que pueden obtener como por los perjuicios que padecen. Sin embargo, existen circunstancias (políticas, económicas, sociales) que permiten sospechar la existencia de una percepción específica del problema por parte de esta población, diferente a la habitualmente manejada en los medios de comunicación. Por ello, se considera como hipótesis de partida del proyecto de investigación bajo el que se realiza este trabajo la existencia de una percepción del proceso, tanto de la población local como de los propietarios foráneos, que permanece oculta y que es necesario hacer aflorar para analizar con rigor el fenómeno y, lo más importante quizá, para poder diseñar herramientas de solución o aminoración de sus efectos. Sin este conocimiento, la comprensión del problema sería limitada.

En este contexto, este trabajo se plantea como objetivo explorar la percepción de la urbanización dispersa en su dimensión paisajística, tanto de la población local como de la población extranjera, en un contexto espacial donde el fenómeno ha adquirido una especial virulencia, los entornos rurales de zonas litorales mediterráneas. Conecta así con varias de las disposiciones del Convenio Europeo del Paisaje, expresadas en la propia definición (cualquier parte del territorio tal y como es percibida por la población...) y en particular en la determinación de los objetivos de calidad paisajística, obtenidos a partir del conocimiento de las aspiraciones de la población en materia de paisaje (Council of Europe, 2000). Igualmente, este conocimiento será de utilidad para establecer procedimientos y herramientas tendentes a la recuperación paisajística de estos terrenos en un contexto de cambios normativos que persiguen la regularización de este fenómeno.

\subsection{Antecedentes}

El urbanismo disperso, el denominado sprawl, es un modelo territorial caracterizado por el crecimiento difuso de la urbanización en los entornos rurales de los espacios urbanos. Definido como 'the physical pattern of low-density expansion of large urban areas, under market conditions, mainly into the surrounding agricultural areas' (European Environment Agency [EEA], 2006, p.6), surge y tiene un mayor desarrollo en Estados Unidos y en los países anglosajones a partir de los años 60 del pasado siglo, pero ha alcanzado también al territorio europeo (Couch, Leontidou y Petschel-Held, 2007; Oueslati et al., 2015), con mayor intensidad desde los años 80, adquiriendo una especial incidencia en la franja mediterránea, donde ha adoptado características propias (Egidi, Cividino, Vinci, Saterino y Salvia, 2020). Responde a diversas causas, entre las cuáles se encuentra el desarrollo socioeconómico, mejoras en los transportes, nuevas orientaciones en política urbanística territorial o ciertos cambios sociológicos, que repercuten en su demanda. En la región mediterránea, el sprawl aparece especialmente vinculado a los espacios litorales, en 
mayor medida que a las grandes urbes (EEA, 2006), relacionado con el desarrollo de determinadas modalidades turísticas, como el denominado turismo residencial, definido por su carácter semi-permanente y por la utilización por estos turistas de viviendas en propiedad, edificadas en el lugar de elección (Leontidou y Marmaras, 2001). En ciertos casos, el foco emisor del urbanismo disperso no se encuentra claramente definido, sino que surge en el interior del propio espacio rural, utilizándose en estos casos el término, más preciso, de rural sprawl (Mann, 2009; Gonzalez-Abraham, et al., 2007), de orígenes y causas diversas según el espacio afectado, como la recuperación de actividades agrícolas y, especialmente, la valorización de las condiciones ambientales del medio rural para la actividad residencial; las ventajas derivadas del precio del suelo o, en su caso, de la ausencia de regulación, aunque también pueden intervenir, se encuentran más vinculadas con el sprawl urbano. Por ello, la expansión del turismo residencial en áreas rurales interiores del entorno litoral mediterráneo, como ocurre en el área de estudio analizada, se ajusta en mayor medida a esta variante rural que al modelo clásico de sprawl.

Como principales procesos territoriales causantes del fenómeno, la segunda residencia y sus interrelaciones con el paisaje y el turismo ha sido tratada por autores como Hall y Müller (2004), mientras que el turismo residencial en la región mediterránea ha sido objeto de estudio de diversos autores (Barke, 1991; Mazón y Aledo, 2005; Módenes y López, 2007). Surgida de la combinación de ambos factores, la urbanización espontánea en el área mediterránea ha sido trabajada en los entornos litorales por Beriatos (2008), mientras Salvati y Gargiulo (2014) han analizado las características de este proceso en diferentes zonas del territorio griego, estableciendo diferencias con el original modelo norteamericano. En otros ámbitos espaciales, el sprawl, que responde a causas muy dispares, ha sido caracterizado en el caso chino por Yue, Liu y Fan (2013), mientras que otros autores han estudiado la incidencia de esta modalidad de crecimiento urbano en regiones latinoamericanas (Inostroza, Baur y Csaplovics, 2013). Las consecuencias del sprawl han sido recogidas en diversas publicaciones que abordan materias como los problemas urbanísticos, la dotación de servicios, el coste medioambiental, la salud (James et al., 2013) o el deterioro social (Morris, 2013).

En España, la extensión del sprawl ha sido estudiada por Hortas-Rico y Solé-Ollé (2010) y por Membrado (2013), que constata el mayor crecimiento del modelo difuso frente al concentrado, asociado a los procesos turísticos. El caso de Madrid ha sido tratado por Díaz Pacheco y García Palomares (2014), y antes por Ezquiaga (1983), que analizó el modelo de segunda residencia en relación a las parcelaciones ilegales, al igual que Burriell (2018) para la Comunidad Valenciana. También centrados en el área mediterránea, Hof y Blázquez-Salom (2013) han analizado el caso de Mallorca, donde se está produciendo un importante desarrollo en el interior de la isla, mientras Morote y Hernández (2016b) han analizado este proceso territorial en la provincia de Alicante, vinculándolo con el desarrollo turístico y con sus consecuencias sobre el consumo de agua. Otros trabajos ponen el acento en la dimensión jurídica y política del fenómeno, como los de Burriel (2009) o Mantecón, Membrado y Huete (2016). La estrecha relación existente entre este desarrollo y la población extranjera ha sido analizada por Morote y Hernandez (2016a) y Membrado (2015). Finalmente, el área de estudio, la comarca de la Axarquía (Málaga), ha sido analizada en sus características, procesos y dinámicas territoriales por autores como Justicia (1988) o Mérida (2019), mientras el problema de las edificaciones ilegales ha sido tratado, entre otros, por Yus y Torres (2010) o Mérida y Perles (2020), que se centran en la utilidad de la integración paisajística como herramienta de política territorial.

\section{Metodología}

\section{1. Área de estudio}

El área de estudio es la comarca de la Axarquía, en la parte oriental de la provincia de Málaga (Figura 1), espacio que constituye una de las muestras más representativas del fenómeno de la urbanización dispersa, tanto por su incidencia (algo más de 20.000 viviendas) como por las repercusiones sociales y políticas que ha traído consigo, ya que ha tenido como protagonista, en un gran número de casos, a población extranjera. Con una superficie de unos $1.026 \mathrm{~km}^{2}$ y una población de 214.323 habitantes, constituye una comarca montañosa excepto en el tramo bajo del valle del río Vélez, eje articulador del territorio, y en la estrecha franja litoral. Se encuentra delimitada por elevados sistemas montañosos al norte y al este (Figura 2), de unos 1.500-2.000 metros de altitud, que encierran un paisaje intrincado de montañas medias de menor altura, pero con fuertes pendientes, y materiales esquistosos. Al norte, una 
depresión intramontana introduce formas más alomadas en el contacto con las alineaciones calcáreas. Por su disposición, estas sierras poseen una relevante función climática, ya que protegen a la comarca de los vientos del norte, lo que, junto a la proximidad del mar y a la exposición meridional de sus terrenos, proporcionan una alta benignidad térmica, factor clave en su desarrollo agrario, turístico y residencial.

Figura 1. Localización del área de estudio

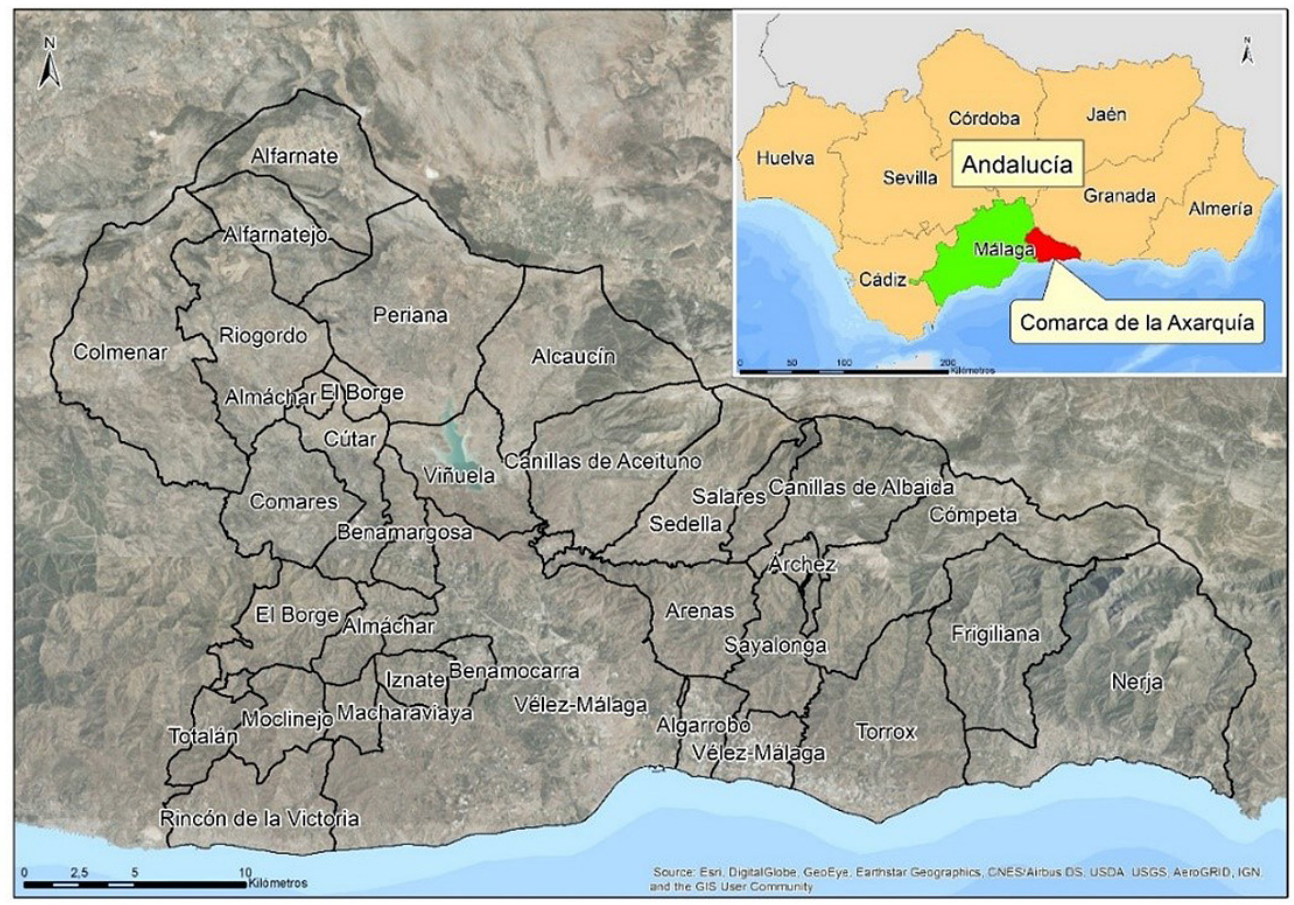

Fuentes: Instituto Geográfico Nacional (2019). Instituto de Estadística y Cartografía de Andalucía (2019). Elaboración propia

Figura 2. Mapa topográfico de la comarca de la Axarquía

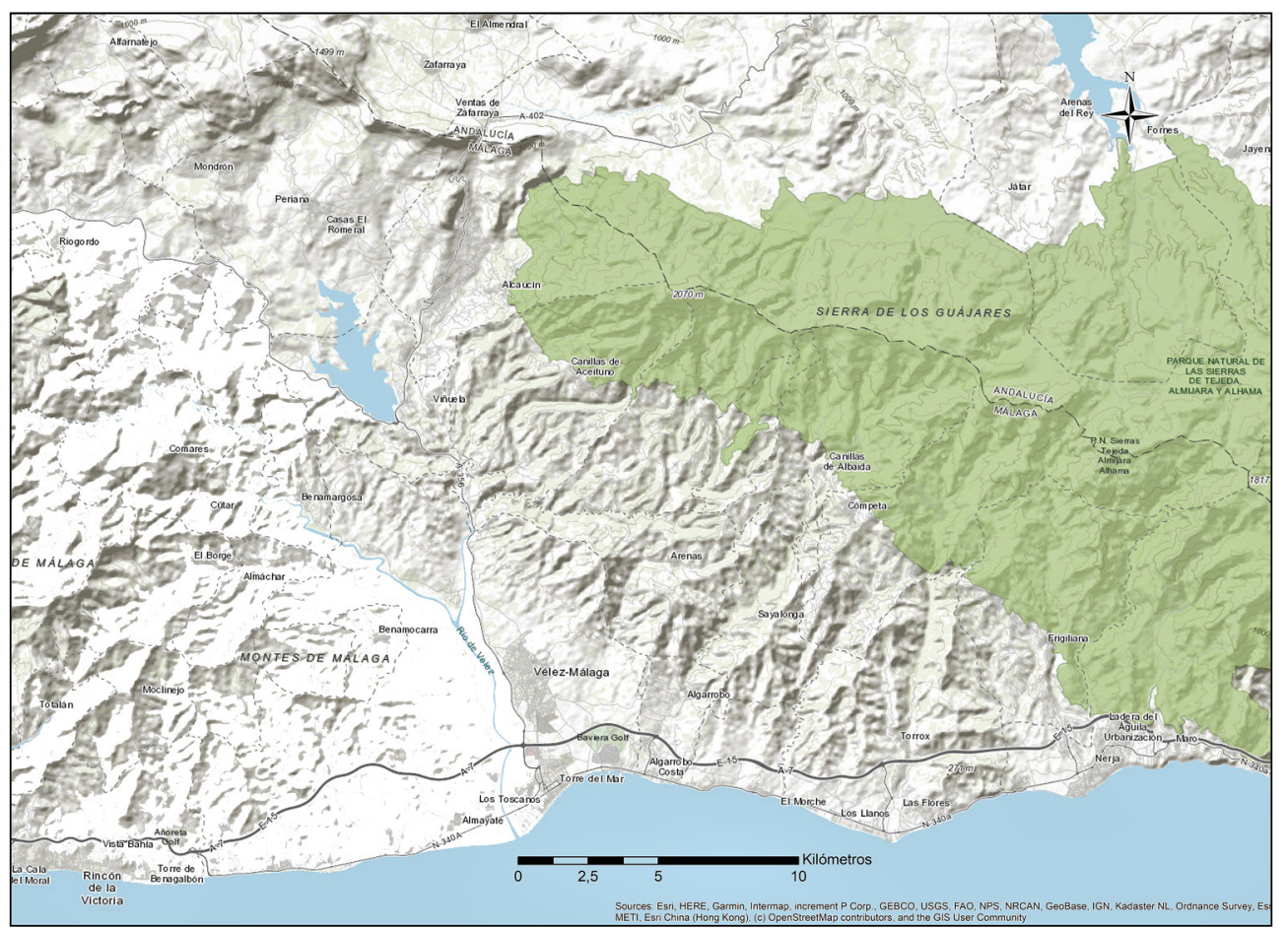

Fuente: ESRI (2021) 
Con excepción de las rocosas sierras perimetrales, en líneas generales se trata de un territorio intensamente humanizado, a pesar de su compleja orografía. La naturaleza pizarrosa de sus materiales, junto con sus condiciones climáticas, han favorecido históricamente la ocupación agraria de sus laderas, primero con la vid, que tuvo una gran expansión durante los siglos XVIII y XIX, y posteriormente, tras la crisis de la filoxera, con especies arbóreas de secano, como el olivo o el almendro. Producto de esta intensa ocupación agraria, y de su accidentado relieve, el poblamiento combinaba tradicionalmente el modelo concentrado, normalmente en pequeños núcleos, con un denso hábitat disperso, resultado de la estructura minifundista de la propiedad. Por ello, el hábitat diseminado, paradójicamente tratándose de un espacio montañoso, formaba parte del carácter de su paisaje.

Este modelo tradicional se reestructuró a partir de la segunda mitad del siglo XX con la crisis del secano, que condujo al despoblamiento, y, simultáneamente, con el auge del regadío, que se tradujo en una potente expansión de dos nuevas modalidades y cultivos agrarios de gran rentabilidad: los invernaderos, en la parte litoral, y sobre todo los frutales subtropicales, que tuvieron su primer emplazamiento en las laderas bajas de los sistemas montañosos pero que se ha terminado extendiendo, debido a su alta rentabilidad, por colinas y llanuras (Figura 3). En la actualidad, la mayor parte de las aproximadamente 770 has. de invernaderos y 10.600 has. de aguacate y mango de la provincia de Málaga se localizan en esta comarca. Al mismo tiempo, el área litoral experimentaba un importante crecimiento urbano, ligado tanto al turismo como al éxodo rural y, más recientemente, al desarrollo metropolitano de Málaga. La mayor parte de los 211.000 habitantes de la comarca se sitúan en el litoral (Rincón de la Victoria, Torrox, Nerja) y en la capital comarcal, Vélez-Málaga, situada en una zona próxima a la desembocadura del río Vélez y que con 80.817 habitantes reúne al 38,4\% de la población de la comarca, en buena parte procedentes de las migraciones desde los núcleos rurales interiores.

Figura 3. Mapa de usos y aprovechamientos del suelo

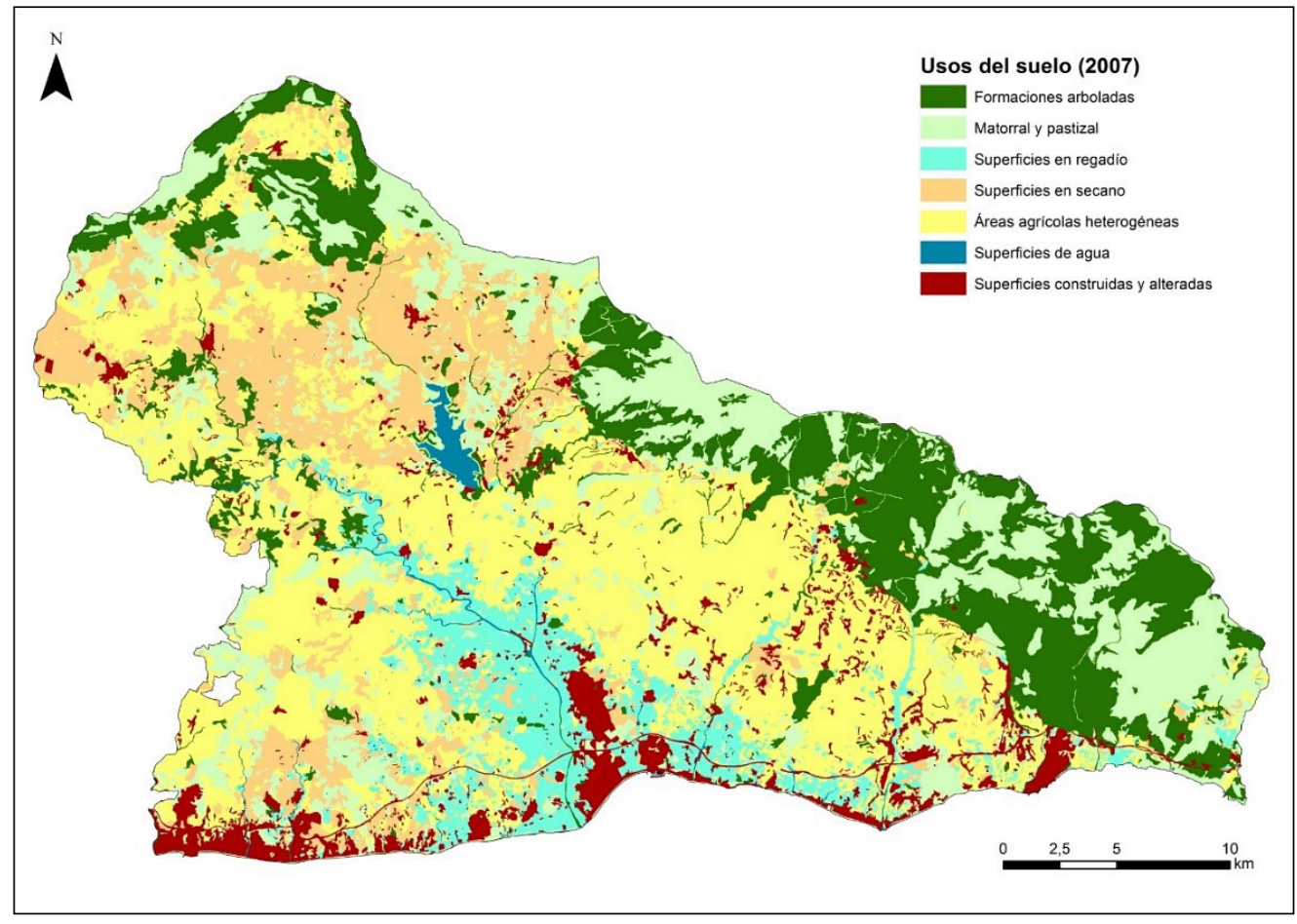

Fuente: Red de Información Ambiental de Andalucía (REDIAM), 2019. Elaboración propia

Quedaron al margen de este progreso económico las zonas montañosas interiores, antiguos dominios del secano, con un caserío en la mayoría de las ocasiones abandonado y con una dinámica demográfica negativa. Estos pequeños núcleos han experimentado un importante descenso de su población, de forma más acusada en las últimas décadas, al mismo tiempo que siguen conservando elevadas tasas de paro (entre el 20 y el 30\%), debido al dominante componente agrario de su actividad económica. Por ello, es previsible que el proceso de despoblación continúe en los próximos años. 
Sobre estos terrenos comenzará un proceso de urbanización difusa a partir de los años 80 ligado a varios procesos territoriales (segunda residencia, rururbanización), entre los que sobresale el turismo residencial, con una importante demanda por parte de ciudadanos extranjeros, británicos principalmente, y en su mayoría jubilados, que aspiraban a residir en entornos rurales o naturales de buenas condiciones climáticas, atractivo paisajístico y cercanía a los servicios básicos. Este fenómeno hizo crecer espectacularmente tanto el número de ciudadanos extranjeros como el número de viviendas dispersas, generando una actividad económica cortoplacista de la que se benefició una parte significativa de la población local, pero que supuso una enorme densificación del hábitat disperso y un importante problema urbanístico, toda vez que estas construcciones se construían mayoritariamente en suelo no urbanizable, ante la preocupante inacción de las administraciones locales. Esto trajo consigo problemas múltiples: urbanísticos (dotación de servicios) y legales, medioambientales (residuos, motorización, etc.) y territoriales, destacando entre ellos el impacto paisajístico. En la actualidad, una vez frenado el proceso por la crisis económica iniciada en 2008 y por las demandas judiciales, se han contabilizado, en el marco del proyecto de investigación en el que se enmarca este trabajo, y a través de la fotointerpretación de datos catastrales, algo más de 20.000 edificaciones dispersas en el conjunto de la comarca, una cifra similar a la estimada por otros autores (Yus y Torres, 2010). La mayoría de las edificaciones son de nueva construcción, siendo escasas las rehabilitaciones de edificaciones preexistentes. Igualmente, la población extranjera residente supone actualmente una parte muy importante de los habitantes de los municipios interiores, con porcentajes superiores al 30\% en muchos de ellos, superando el $40 \%$ en municipios como Cómpeta, Viñuela o Sayalonga (Instituto de Estadística y Cartografía de Andalucía, 2020).

El sprawl así generado en estas zonas de media montaña, de densidades muy elevadas, tiene una particularidad que lo asemeja más a la variante denominada como rural sprawl: no cuenta con un foco claro de irradiación (ver Figura 4). Ni los núcleos interiores, de escaso tamaño, dan lugar a este proceso, ni tampoco el pujante litoral, del que tienden a alejarse la mayoría de edificaciones, exceptuando la parte oriental de la comarca. Si se pretende encontrar algún patrón, quizá el más definido sea la cercanía a las altas montañas (en la actualidad Parque Natural de Sierras de Tejeda, Almijara y Alhama), conformándose en determinadas zonas una especia de orla de urbanización dispersa en torno a estas montañas (Figura 5).

Figura 4. Mapa de calor de edificaciones dispersas (método Hot-Spot)

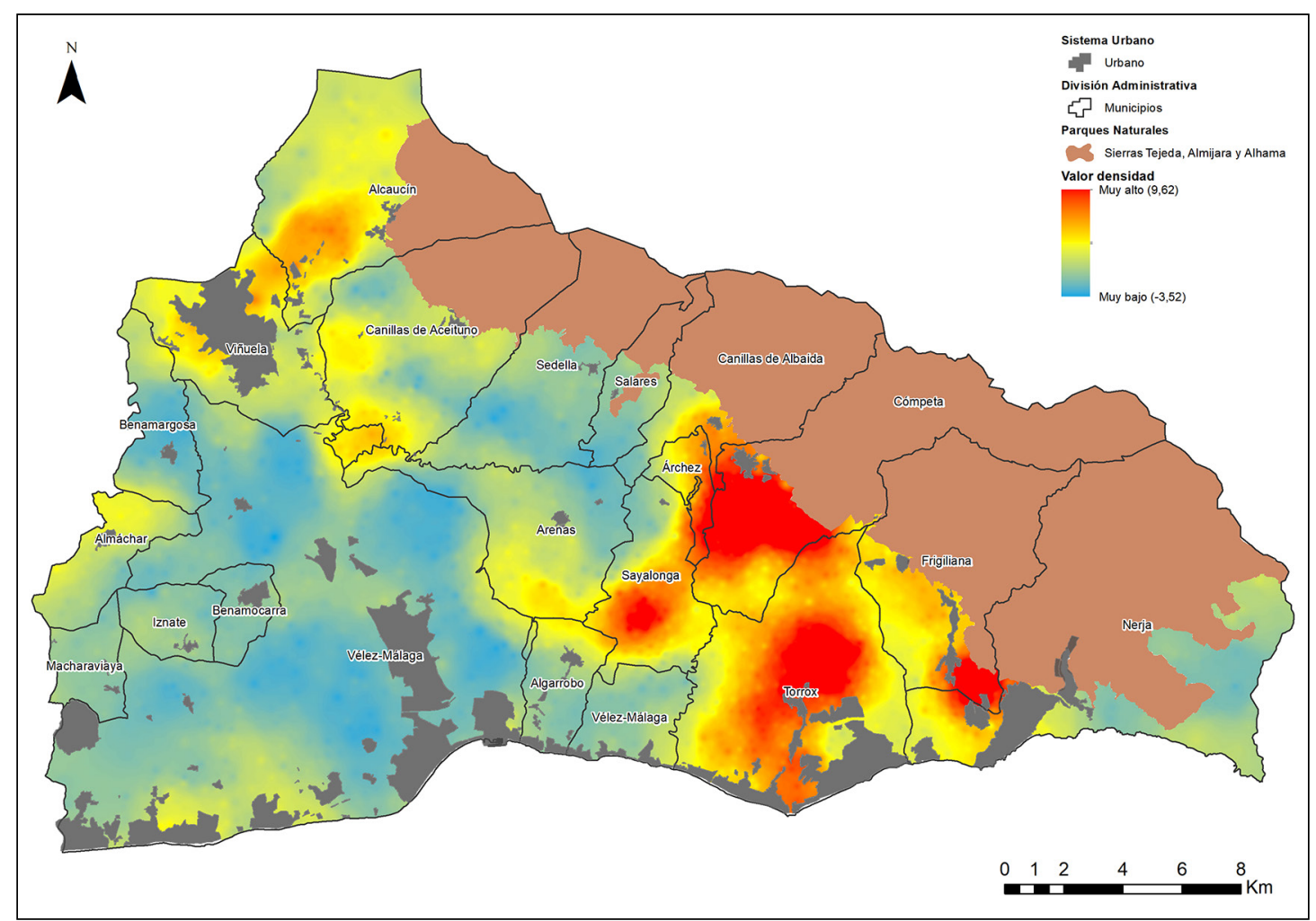

Elaboración propia 
Figura 5. Concentración de edificaciones dispersas en las cercanías del Parque Natural

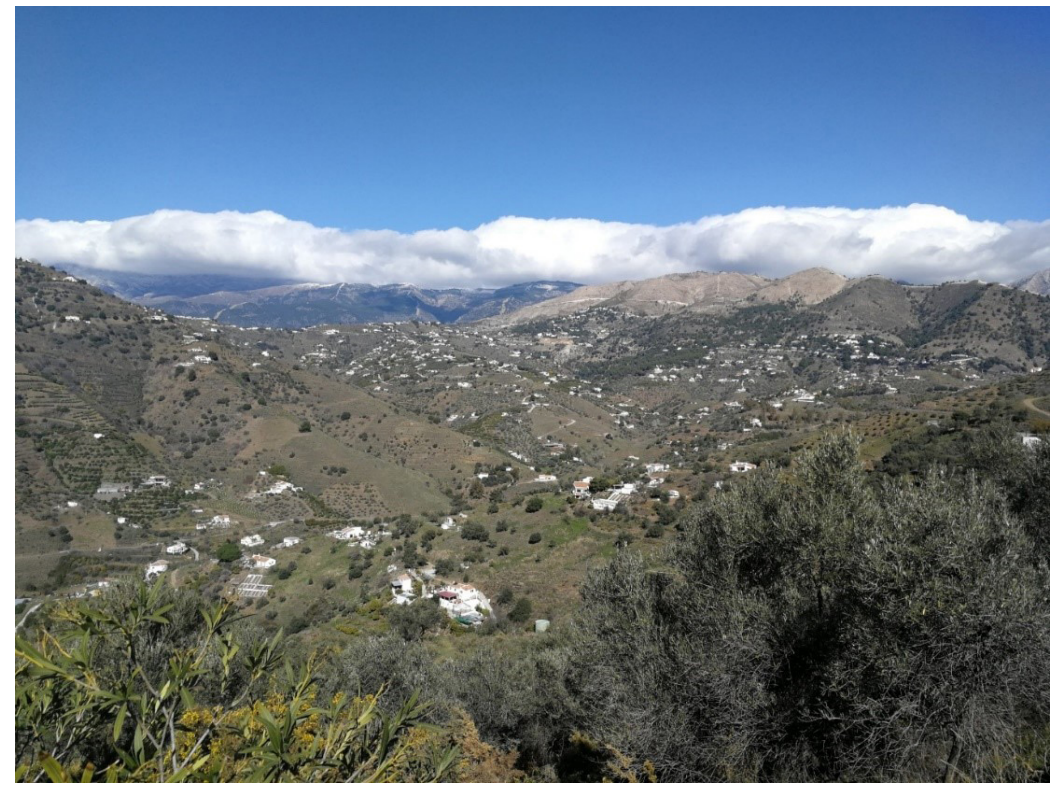

Fotografía de los autores

\subsection{Etapas metodológicas y fuentes}

La metodología empleada para la elaboración de este trabajo ha seguido seis fases metodológicas. La primera ha consistido en la selección de los grupos de población, tanto tipológica como espacialmente. Para ello se seleccionaron tres grupos de población: residentes extranjeros en viviendas dispersas, población local residente en pequeños núcleos y miembros de asociaciones culturales de la comarca. El primer grupo, un colectivo tradicionalmente reservado y de difícil acceso, se conformó con la ayuda de SOHA (Save Our Homes Axarquía), asociación creada en defensa de sus intereses como propietarios de estas viviendas. Las entrevistas a la población local residente en pequeños núcleos se realizaron en las localidades de Almachar, Alcaucín y Sedella, seleccionadas por considerarse representativas de diferentes ámbitos espaciales existentes en la comarca (occidental/oriental, montaña media/estribaciones de altas cordilleras) y que han recibido una diferente incidencia del fenómeno de urbanización dispersa (alta en Alcaucín, media en Sedella y baja en Almachar). Para la gestión de la organización de las entrevistas (selección de grupos, lugar y fecha de realización) se contó con la colaboración de responsables y técnicos municipales. Finalmente, las tres asociaciones culturales entrevistadas (Asociación cultural Bezmiliana, de Rincón de la Victoria, Asociación Amigos de la Cultura de Velez-Málaga, Club de Fotografía de Nerja) se radicaban en los municipios más poblados, realizándose en estos casos el contacto con ellas de forma directa.

La segunda etapa metodológica la supuso el diseño de los cuestionarios, que combinan preguntas de respuesta cerrada o semicerrada con ítems orientados a la evaluación de pares de fotografías, relativas a diversas temáticas, y proyectadas en una pantalla durante la sesión. Esta última parte era común a los tres grupos, mientras que las preguntas de respuestas cerradas o semicerradas tenían una parte común y otra específica a cada grupo, por lo que se diseñaron 3 modelos de cuestionarios. Estos cuestionarios ser realizaron en español y, en el caso de los residentes extranjeros, en inglés, constando de 33 ítems y 24 pares de fotografías. Dado el especial protagonismo que adquiere en esta temática, se profundizó específicamente en el cuestionario en la caracterización del grupo de residentes extranjeros, un colectivo, como se ha mencionado, normalmente poco accesible.

La tercera fase metodológica ha consistido en la selección de las muestras de hábitat disperso y la posterior realización de fotografías in situ, mediante trabajo de campo, para obtener las imágenes que se incluirían definitivamente en el cuestionario. La determinación de los casos a muestrear parte del análisis de la información disponible en la base de datos geoespacial que el proyecto de investigación había generado sobre edificaciones dispersas en la comarca. Una vez establecida la población a encuestar y diseñados los cuestionarios, la cuarta fase metodológica la supuso la realización de las encuestas. Se llevaron a cabo por grupos de población y de forma conjunta para todos sus componentes, lo que implicó la concertación de citas con los grupos, la búsqueda de un local apropiado (que permitiera la proyección de imágenes) y la propia ejecución 
de la encuesta, que se desarrollaba durante unos 45 minutos aproximadamente. Se realizaron un total de 137 encuestas, durante finales de 2018 y primeros meses de 2019, estructuradas de la siguiente forma: residentes extranjeros (42 encuestas), miembros de asociaciones culturales de la comarca (41 encuestas) y población local residente en pequeños núcleos (54 encuestas). Una vez realizadas, las dos últimas etapas metodológicas las constituyeron, respectivamente, la tabulación de la información generada en la encuesta y el análisis de los resultados obtenidos. Por último, es necesario resaltar que el proyecto de investigación en el que se enmarca este trabajo conllevó también la realización de entrevistas personalizadas a actores sociales. Aunque no se ha explotado esta información en este trabajo, puntualmente se recurre a algunos de sus resultados para corroborar determinadas conclusiones vinculadas a ciertos apartados de las encuestas.

\section{Resultados}

Atendiendo en primer lugar a la caracterización general de los encuestados, se trata de ciudadanos con residencia en 14 de los 31 municipios de la comarca, que abarcan núcleos tanto litorales como interiores y de diferente tamaño de población. Por edad, se sitúan mayoritariamente en las franjas de edad de entre 30 a 65 años y de 65 y más años (48\% y 47\% respectivamente), suponiendo los menores de 30 años únicamente el 5\%. Esta distribución acentuadamente envejecida se explica por la edad media de los miembros de las asociaciones y, fundamentalmente, por la avanzada edad media de los encuestados de la población local y, sobre todo, de la población extranjera residente: algo más del $80 \%$ de los encuestados pertenecientes a este último grupo son mayores de 65 años, respondiendo al perfil característico de este grupo de población, formado mayoritariamente por jubilados. Por otra parte, los núcleos en lo que se ha encuestado a la población local cuentan igualmente con una población sensiblemente envejecida, alcanzando los mayores de 65 años más del 33\% de la población en municipios como Alcaucín y Sedella, prácticamente el doble, por tomar una referencia cercana, del porcentaje que posee la ciudad de Málaga (17,6\%) (INE, 2019).

Respecto a la caracterización específica de los encuestados extranjeros, los resultados confirman su condición de jubilados (90\%), sobre todo de nacionalidad británica, que se han trasladado a esta comarca en los últimos 20 años, y que en su mayoría residen en estos municipios de forma permanente (67\%), en unidades familiares de dos personas (93\%). En su práctica totalidad viven en edificaciones aisladas, aunque no muy alejadas de algún núcleo de población. Normalmente poseen parcelas relativamente amplias (más de $500 \mathrm{~m}^{2}$ ), mientras que las viviendas son sustancialmente de menores dimensiones (100-200 $\mathrm{m}^{2}$ ). La mayoría de las propiedades cuenta con piscina, dedicando una parte de la parcela para el cultivo en algo más de la mitad de los casos, casi en todos ellos para consumo personal.

Los resultados de naturaleza temática, obtenidos del cuerpo de la encuesta, se han estructurado en 4 apartados, que se exponen a continuación: en el primero de ellos se analizará la percepción general del paisaje de la comarca; en el segundo apartado, los resultados derivados de las apreciaciones sobre el modelo de urbanización dispersa; posteriormente, se abordará la percepción de las interrelaciones entre paisaje y urbanización dispersa, con preguntas específicas sobre la densidad de viviendas, emplazamientos, modelos de agrupación o tipologías arquitectónicas; finalmente, se analizarán las valoraciones manifestadas por los encuestados sobre las perspectivas futuras del paisaje en la comarca.

\subsection{Percepción del paisaje de la comarca}

En distintos puntos del cuestionario se abordaba, como primera aproximación a los objetivos de la encuesta, la percepción del paisaje de la comarca, su relevancia y su estado actual. Respecto a este último punto, la visión de los encuestados es moderadamente positiva: el 53\% de los encuestados consideraban que su estado era positivo, aunque un $44 \%$ lo percibe como mejorable, mientras que sólo el $3 \%$ lo consideraba claramente negativo. Estos datos marcan el punto de partida del trabajo: la población valora su paisaje, aunque existe una considerable visión crítica sobre su estado. Por grupos, la población extranjera es la que se sitúa en valores próximos al promedio; de hecho, el paisaje es muy importante para ellos: junto al clima y a la tranquilidad, es el motivo más esgrimido en su decisión de vivir en esta zona, y por esta razón la gran mayoría de sus viviendas cuentan, según afirman, con vistas panorámicas. Pero las diferencias significativas en la percepción del estado del paisaje surgen entre la población local y los miembros de las asociaciones. Mientras que los primeros lo perciben de una manera más optimista (69\% lo califican de positivo), para los segundos, más críticos, el porcentaje baja al $28 \%$, alcanzando el $62 \%$ los que lo califican de mejorable (Figura 6). Se puede inferir en esta valoración la influencia que posiblemente puede tener el nivel cultural (habitualmente más elevado entre los miembros de las asociaciones) y valores como la concienciación ciudadana o el activismo, también, por su propia naturaleza, más extendidos entre este grupo. 
Figura 6. Percepción general del estado del paisaje en la comarca

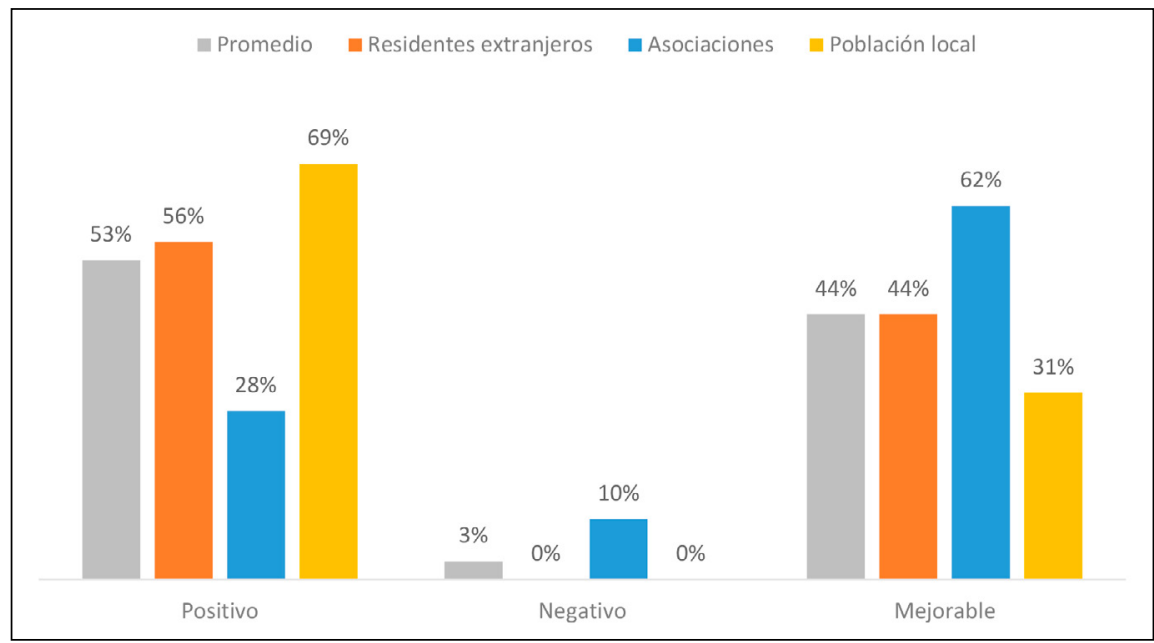

Elaboración propia

\subsection{Valoración del modelo de urbanización dispersa}

De forma general, el fenómeno de la urbanización dispersa en la comarca es contemplado en su conjunto de forma positiva, juzgándolo favorablemente el 68\% de los encuestados, mientras que sólo el 28\% lo hace de forma negativa. Aunque no se preguntaba por las motivaciones, se infiere que en las respuestas el peso del dinamismo económico que genera esta actividad ejerce un papel importante, aunque es interesante resaltar que, como se verá más adelante, esta justificación económica tiene también su equivalencia en la valoración paisajística. Lógicamente, los propietarios extranjeros acentúan la opinión positiva (un 90\%), atendiendo a sus propios intereses, aunque hay que indicar también que los miembros de este colectivo consideran que sus propiedades suponen un importante revulsivo económico para la comarca (construcción, mantenimiento, consumo, etc.). Resulta de nuevo más llamativa la disparidad de opiniones existente entre los dos grupos de población española. Mientras que el 73\% de los residentes en pequeños núcleos valoran positivamente las construcciones dispersas, esta cifra baja al 38,5\% entre los miembros de las asociaciones culturales, grupo en la que es mayoritaria la percepción negativa (48,7\%), como se puede observar en la Figura 7 . Como ya se ha comentado, el perfil crítico se encuentra más acentuado entre los miembros de las asociaciones.

Figura 7. Valoración del modelo de urbanización dispersa en la comarca

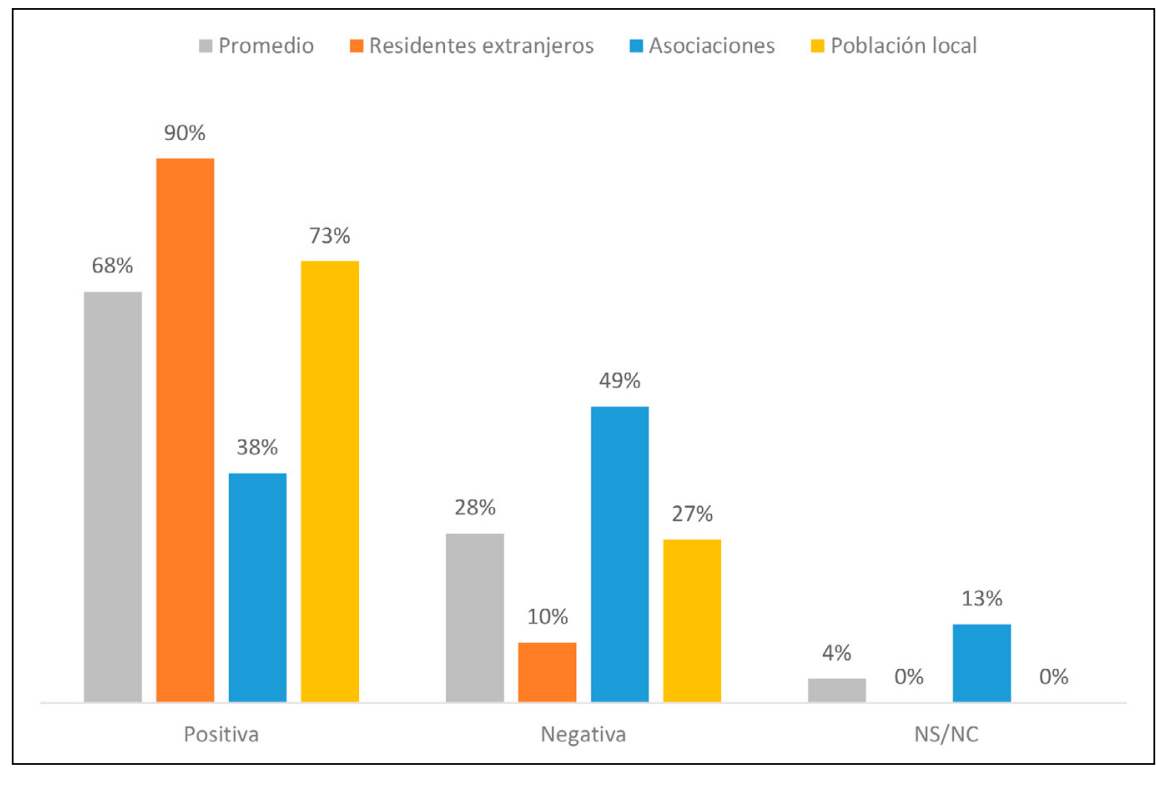

Elaboración propia 
Para confirmar esta tendencia globalmente favorable a la edificación dispersa, en otro punto del cuestionario se interrogaba a los encuestados si estaban de acuerdo con que se permitiera, legalmente, construir libremente en el espacio rural. En general, esta posibilidad es rechazada, si bien cuenta con un apoyo nada desdeñable (ver Figura 8). El 62\% opina en contra de esta liberalización, mientras un 36\% estaría de acuerdo. Hay que tener en cuenta que en las respuestas negativas se uniría, tácitamente, tanto la oposición a las edificaciones dispersas como el rechazo a la construcción de nuevas viviendas, sin implicar necesariamente esta segunda motivación asumir la primera. Entre los residentes extranjeros, las respuestas siguen una proporción prácticamente idéntica a la media. En un colectivo acusado de irregularidades urbanísticas y de impactos medioambientales, se rechaza la posibilidad de ampliación del número de edificaciones, cuya masificación, al mismo tiempo, reduciría su calidad de vida. Entre los miembros de las asociaciones el grado de rechazo es todavía mayor, superando el $82 \%$; sin embargo, entre la población local se impone la opinión favorable, un $58 \%$ frente a un $42 \%$ que piensa en sentido contrario. Detrás de este dato, que camina en sentido contrario al del resto de los grupos encuestados, posiblemente se esconde tanto la apuesta por el mantenimiento de una actividad económica más, en un contexto laboral difícil, como la manifestación de una sociedad rural fuertemente influida por su tradición minifundista, que consiguientemente conlleva una capacidad de decisión absoluta sobre su parcela.

Figura 8. Opinión sobre la posibilidad de construir libremente en espacios rurales

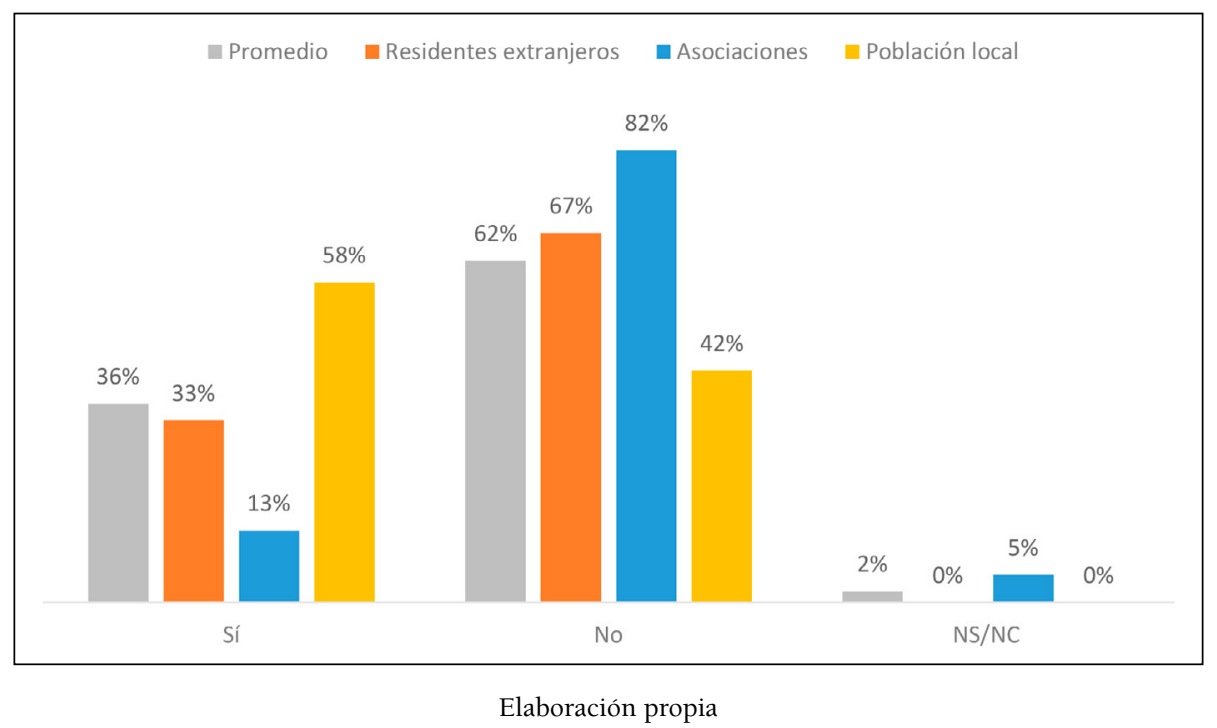

\subsection{Percepción de las interrelaciones entre paisaje y urbanización dispersa.}

El efecto sobre el paisaje de las edificaciones dispersas se planteaba, en un primer ítem, de forma genérica y sin argumentos prefijados, preguntando directamente si las casas aisladas mejoraban o empeoraban el paisaje, más una tercera opción ('depende de la zona') que por un lado evitaba la imprecisión de valorar conjuntamente una comarca de unos $1.000 \mathrm{~km}^{2}$, pero que por otro se convertía en un refugio para la respuesta que no tenía un sentido muy definido. En conjunto, esta última fue la opción más elegida, con un $60 \%$ de las respuestas, mientras que un $21 \%$ de los encuestados entiende que mejora el paisaje y un $19 \%$ considera que lo empeora, unos porcentajes muy parecidos. Sin embargo, dentro de este promedio, resultan llamativas las diferencias en las respuestas de los diferentes grupos. Mientras sólo un 5\% de los miembros de las asociaciones piensa que mejoran el paisaje (un 38\% opina en sentido opuesto), el porcentaje asciende al $24 \%$ entre la población extranjera (donde se refuerza también la respuesta 'depende del lugar', con un 64\%), y hasta un 31\% entre la población local. En ambos grupos de población, los que consideran que mejora el paisaje duplican e incluso triplican a los que opinan que lo empeora (Figura 9), aunque estos alcanzan un nada despreciable $12 \%$ de las opiniones entre los propios propietarios extranjeros. En todo caso, la diferencia más llamativa entre las respuestas tiene que ver con las opiniones mostradas por la población local respecto a la de los miembros de las asociaciones, que se manifiestan de forma prácticamente inversa en las valoraciones más definidas: respectivamente un $31 \%$ y un 38\% de las respuestas consideran que mejoran el paisaje, mientras que un $10 \%$ y un $38 \%$, también respectiva- 
mente, consideran que lo empeoran. Como se apuntó anteriormente, el respaldo de la población local a la construcción dispersa no es, por tanto, únicamente económico, sino que es también, en cierta medida, de naturaleza paisajística.

Figura 9. Valoración del efecto sobre el paisaje de las edificaciones aisladas

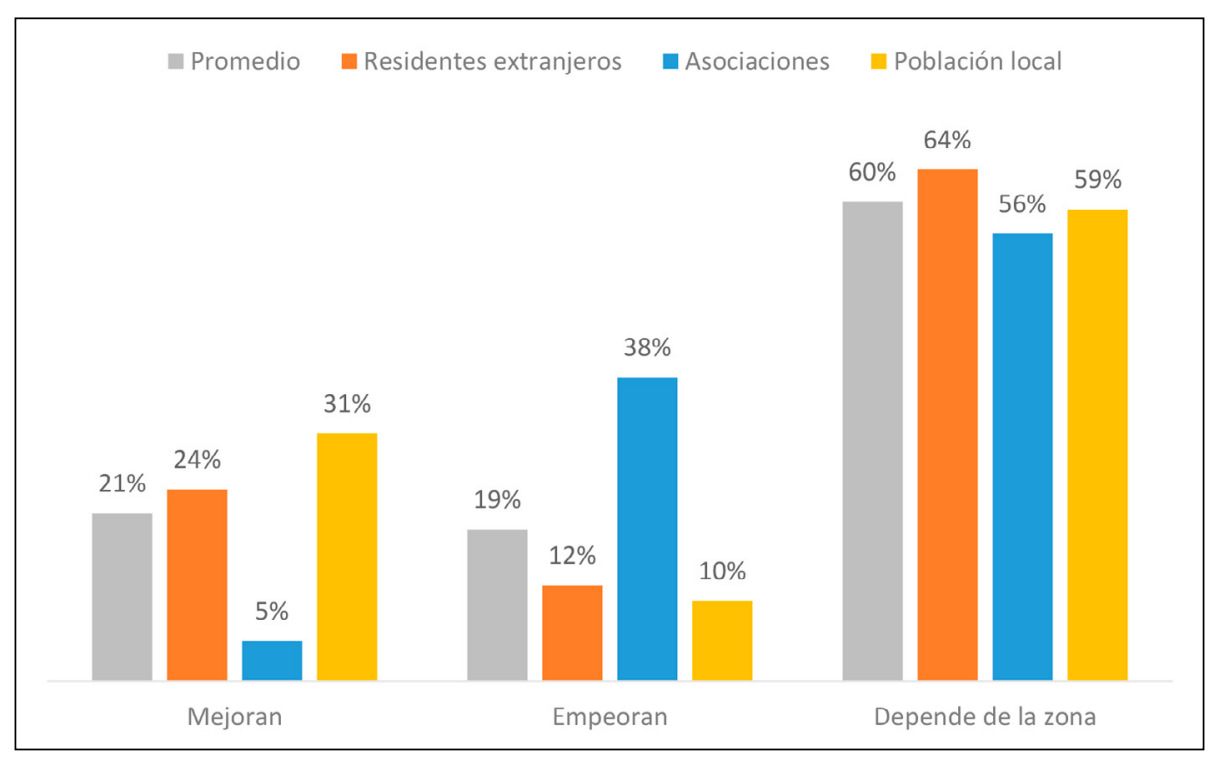

Elaboración propia

Profundizando en esta cuestión, los encuestados son conscientes, mayoritariamente, del impacto paisajístico provocado por, al menos, algunas de estas viviendas: el 70\% piensa de este modo, pero mientras que en las asociaciones el porcentaje alcanza el 90\%, o entre los mismos propietarios extranjeros llega al $74 \%$, entre la población local las respuestas críticas con únicamente algunas construcciones se quedan en un escaso 50\%, mientras los que lo niegan suben al 33\%, lo que confirma la existencia, entre la población local, de una sólida corriente de opinión favorable a estas construcciones, también desde el punto de vista paisajístico o, como mínimo, la inocuidad de estas construcciones (Figura 10). En otros términos: sí el impacto sobre el paisaje de sólo alguna actuación únicamente es admitido por la mitad de los residentes locales, se deduce que para este grupo de población la mayoría de las edificaciones al menos no producen efectos negativos sobre el paisaje.

Figura 10. Percepción de impactos sobre el paisaje de algunas construcciones dispersas

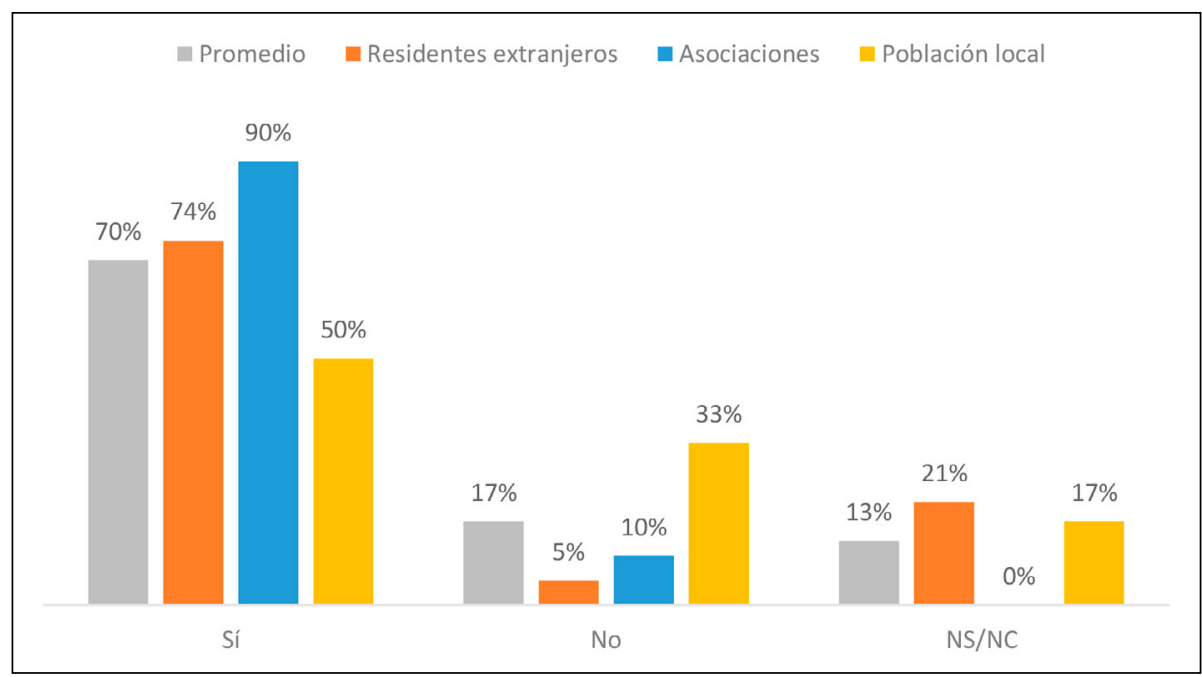

Elaboración propia 


\subsubsection{Apreciaciones sobre la densidad de edificaciones dispersas}

El impacto paisajístico de estas edificaciones obedece, en una primera valoración, a su densidad, muy elevada en la Axarquía, por lo que se ha indagado sobre esta cuestión en varios puntos de la encuesta. Dado que la percepción de la densidad sobre el conjunto de la comarca podía resultar compleja, ya que existen diferentes grados de densidad, se optó por preguntar por el exceso de densidad en algunas zonas (sin que tuvieran que ser concretadas), lo que implicaba una percepción del problema de mínimos. En general, la mayoría de los encuestados son conscientes de que se ha superado una especie de umbral de saturación, al menos, en algunas zonas de la comarca, contestando en este sentido el $68 \%$ de los encuestados (Figura 11), pero mientras que los propietarios extranjeros se sitúan, de forma en cierta medida autocrítica, en ese promedio, los miembros de las asociaciones elevan el porcentaje al $85 \%$, algo que se corresponde con la actitud crítica de este colectivo. Por el contrario, la población local reduce al 54\% esta percepción, que, aun siendo mayoritaria, implica una cierta concesión únicamente en determinadas zonas; además, duplica el promedio los que opinan, dentro de este grupo, que no se ha construido excesivamente en ningún lugar ( $27 \%$ frente al $12 \%$ de promedio), lo que refuerza la existencia de un potente eje de percepción positiva de este fenómeno entre la población local.

Figura 11. Valoración sobre la excesiva construcción de viviendas en algunas zonas

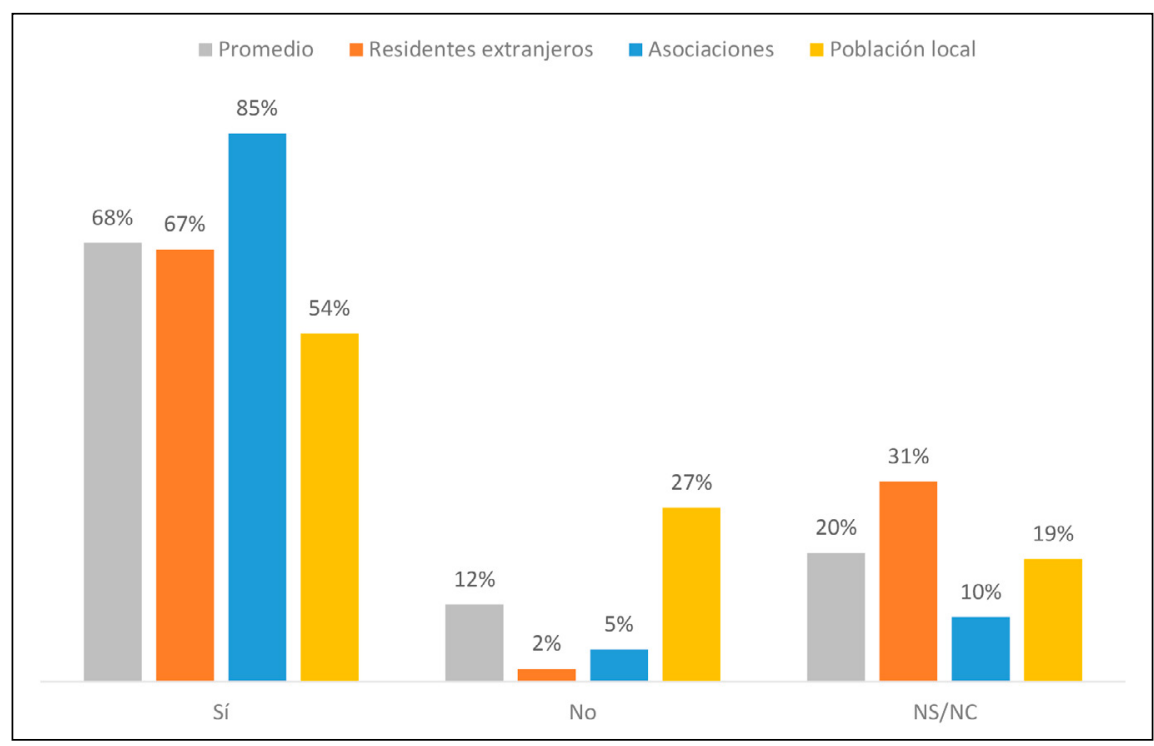

Elaboración propia

Figura 12. Ejemplo de par fotográfico para preferencias de densidades (alta/baja)
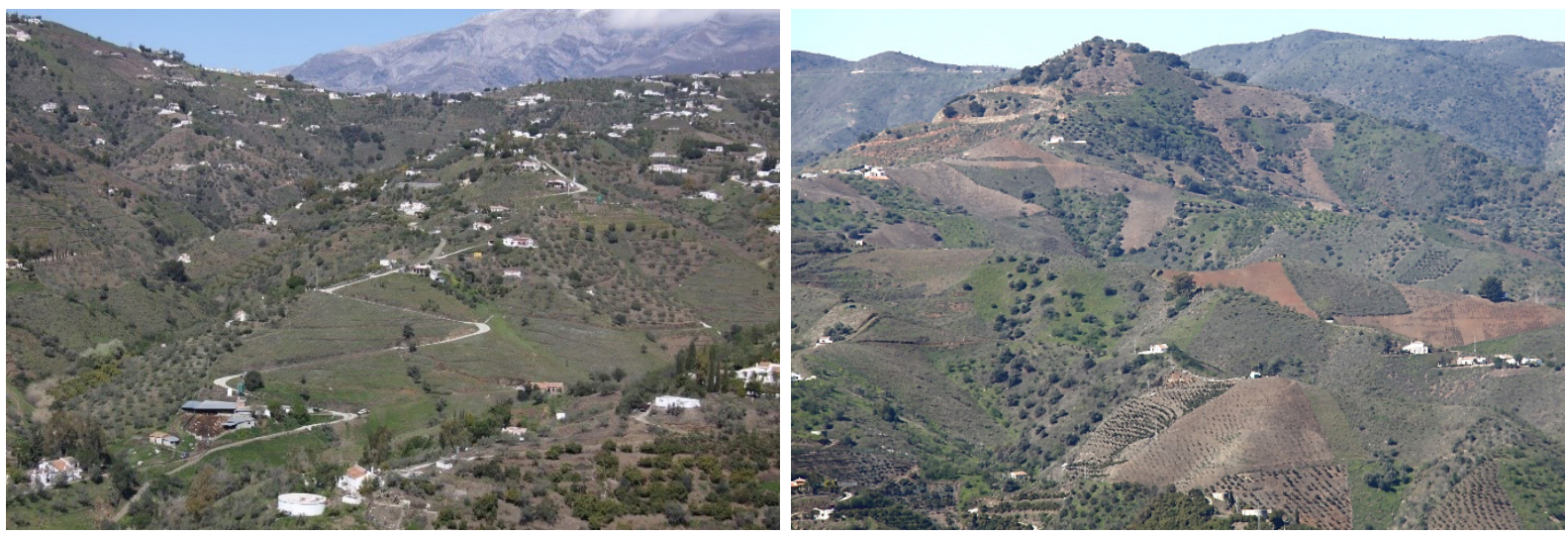

Fotografías de los autores

Con el objetivo de confirmar la valoración paisajística de la densidad de edificaciones dispersas, tres de los pares de fotografías incluidos en la encuesta mostraban zonas con diferentes grados de densidad 
de construcciones (ver ejemplo en Figura 12). En general (Figura 13), de las respuestas se puede concluir que son ligeramente preferidas por los encuestados, en conjunto, las densidades altas y media-altas $(52 \%))$ en lugar de las bajas y media-bajas (48\%). Este dato contrasta con la existente percepción técnica, mediática y académica sobre el impacto de estas construcciones, y sirve de puntualización a las respuestas anteriormente expuestas sobre los efectos de la densidad, que únicamente consideraba los efectos negativos sobre el paisaje de ciertas zonas. Hay que resaltar, de nuevo, la existencia de fuertes disparidades entre los grupos: la tendencia hacia densidades elevadas está más claramente marcada entre la población extranjera y la población local (61\% y 64\% respectivamente) que entre los miembros de asociaciones (26\%), entre los que son mayoría las preferencias por densidades bajas o muy bajas (74\%).

Figura 13. Preferencias sobre densidad de viviendas en pares de fotos ( $A=$ alta y media alta; $B=$ Baja y media baja $)$

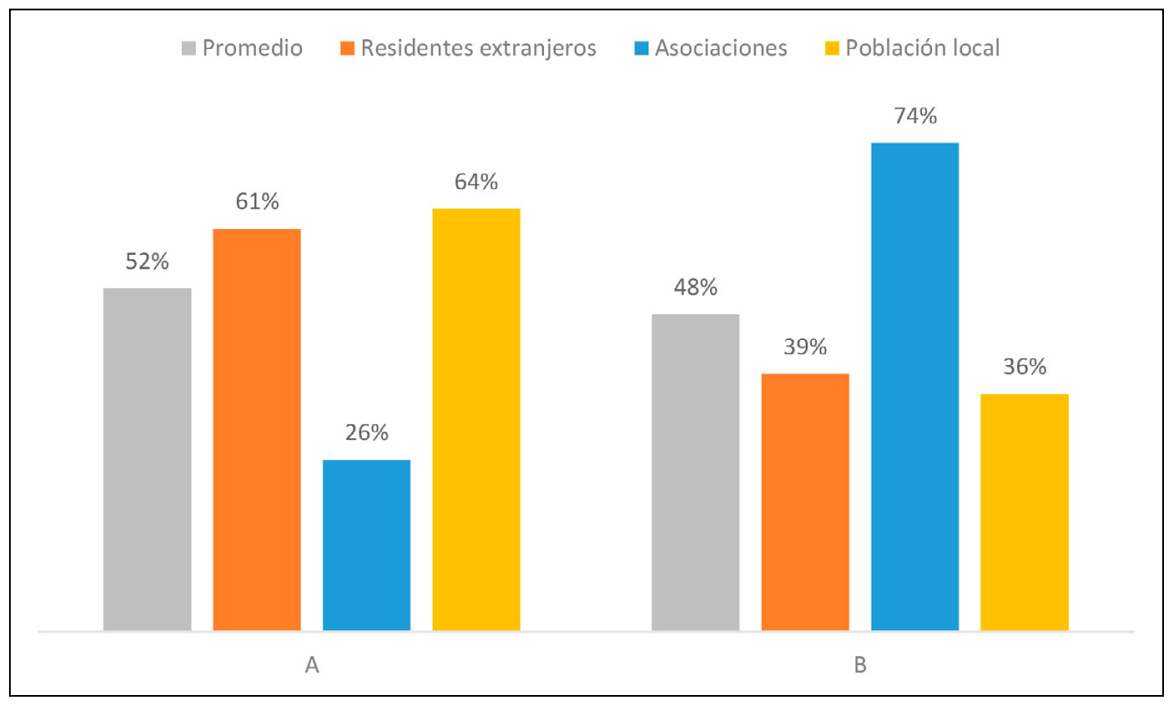

Elaboración propia

\subsubsection{Valoraciones sobre modelos de agrupamiento y emplazamientos}

Las edificaciones dispersas no siguen un mismo patrón de organización espacial, sino que responden a dos modelos generales: el modelo concentrado en pequeños asentamientos, a modo de caseríos, sin llegar a producir adosamientos, y el modelo completamente aislado. Por ello, resultaba de interés conocer también la percepción de los encuestados sobre ambos tipos, incluyendo ejemplos de ellos en diversos pares de imágenes (ver ejemplo en Figura 14). En general, como se puede observar en la Figura 15, hay una ligera preferencia por el poblamiento disperso frente al concentrado en pequeñas entidades $(51 \%$ frente a $45 \%$ ), aunque este dato general encierra una marcada diferencia: mientras que las asociaciones apuestan claramente por el poblamiento en pequeños grupos (59\%), buscando probablemente limitar los efectos de la urbanización sobre el territorio, los residentes extranjeros apoyan en mayor medida el poblamiento disperso $(71 \%)$, coincidente en alto grado con sus viviendas, pero también percibido, en esencia, de forma más integrada en el paisaje. La población local, en este caso, no posee una preferencia marcada sobre ambos patrones, equilibrando los resultados. Resultan de interés estos datos si se tiene en cuenta que la Administración apuesta de forma decidida por el modelo concentrado, algo que no suscita un apoyo claro entre los encuestados.

También se preguntaba mediante el mismo procedimiento (elección entre pares de fotos) sobre los emplazamientos de las viviendas, un factor determinante de su impacto paisajístico. Para su inclusión en la encuesta se han seleccionado los emplazamientos en cumbres (principales o de interfluvios secundarios), laderas, valles y llanuras, mostrándolos combinados en varios pares de fotos (ver ejemplo en Figura 16). Hay, en general, una preferencia marcada por los emplazamientos amables, tanto en valles (66\%) como en llanuras (60\%), generando un cierto rechazo las ubicaciones en cumbres y laderas. Estos resultados tienden a valorar la menor intervención en el paisaje y la mayor aptitud de los terrenos para la construcción. Sin embargo, es necesario destacar que el poblamiento disperso tradicional en la comarca tenía como uno de sus emplazamientos preferentes las líneas de cumbre de los interfluvios, dado que unía una topografía relativamente llana con la mayor cercanía a los cultivos, desarrollados, en buena parte, en 
las montañas medias de la comarca. Este emplazamiento tradicional es algo más tenido en cuenta por la población local (54\%), mientras que genera más rechazo entre los miembros de las asociaciones (42\%), que posiblemente penalizan la mayor visibilidad de las construcciones emplazadas en líneas de cumbres. Inversamente, por el efecto contrario, la amplitud de vistas, estos emplazamientos en cumbre tienen también una mayor valoración entre los residentes extranjeros (Figura 17).

Figura 14. Ejemplo de par fotográfico para preferencias sobre organización espacial (caseríos/aislado)
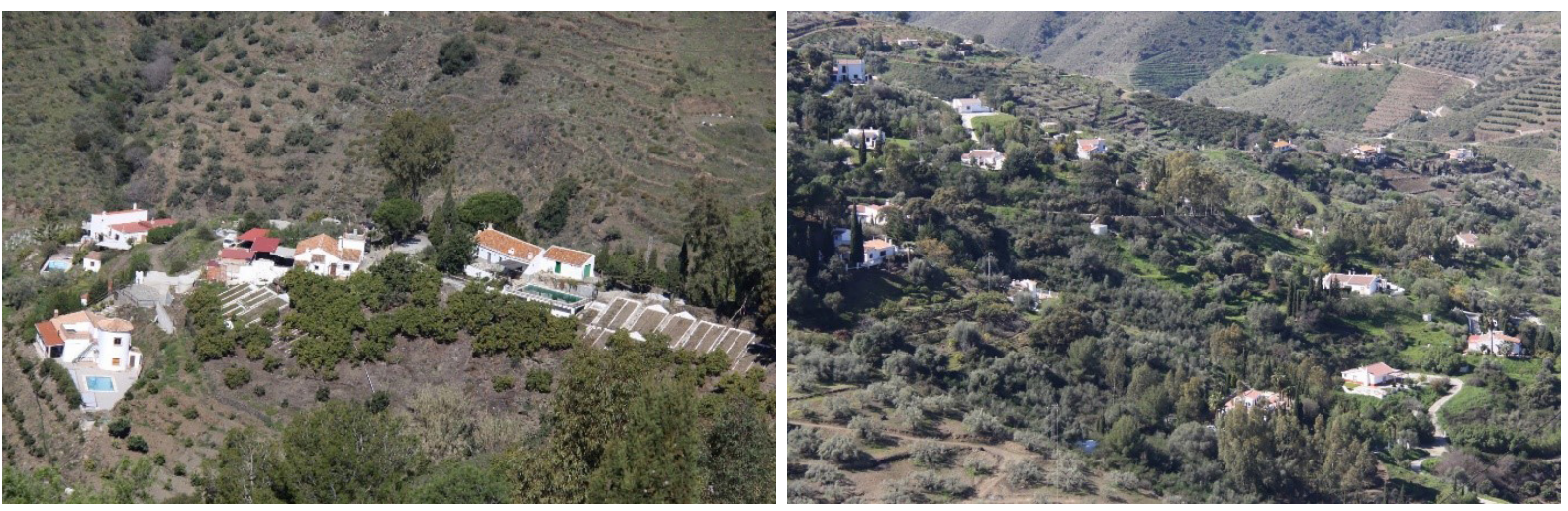

Fotografías de los autores

Figura 15. Preferencias sobre modelo de organización espacial $(A=$ concentrado; $B=$ disperso)

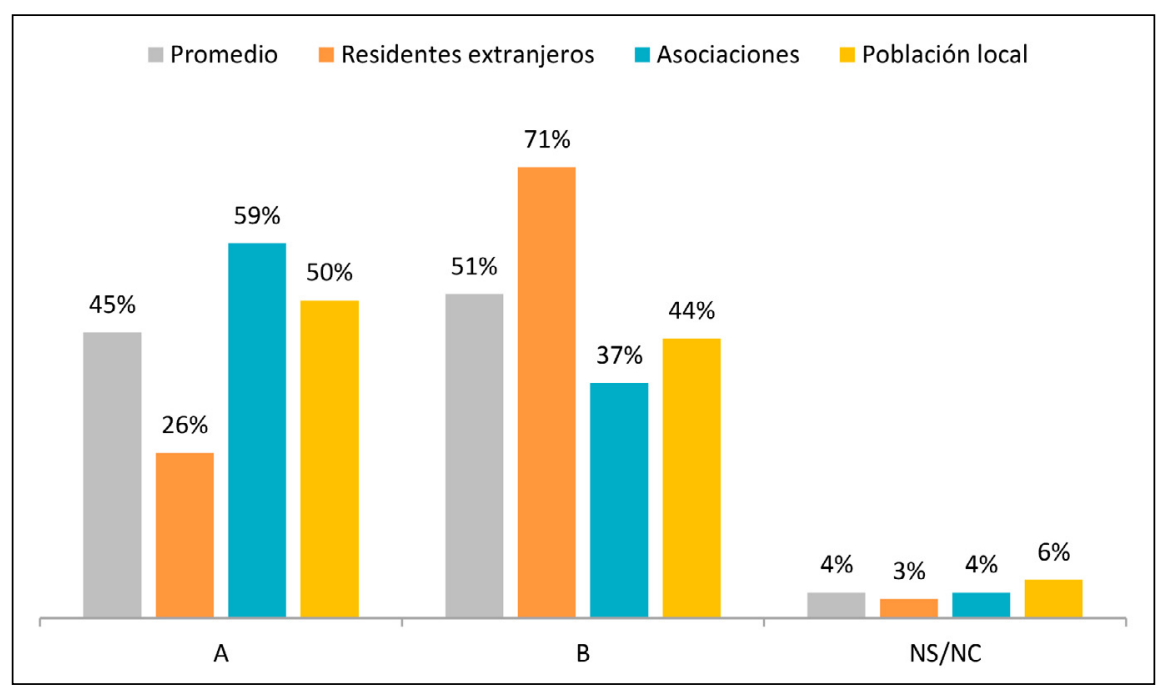

Elaboración propia

Figura 16. Ejemplo de par fotográfico para preferencias sobre emplazamientos (cumbres/laderas)
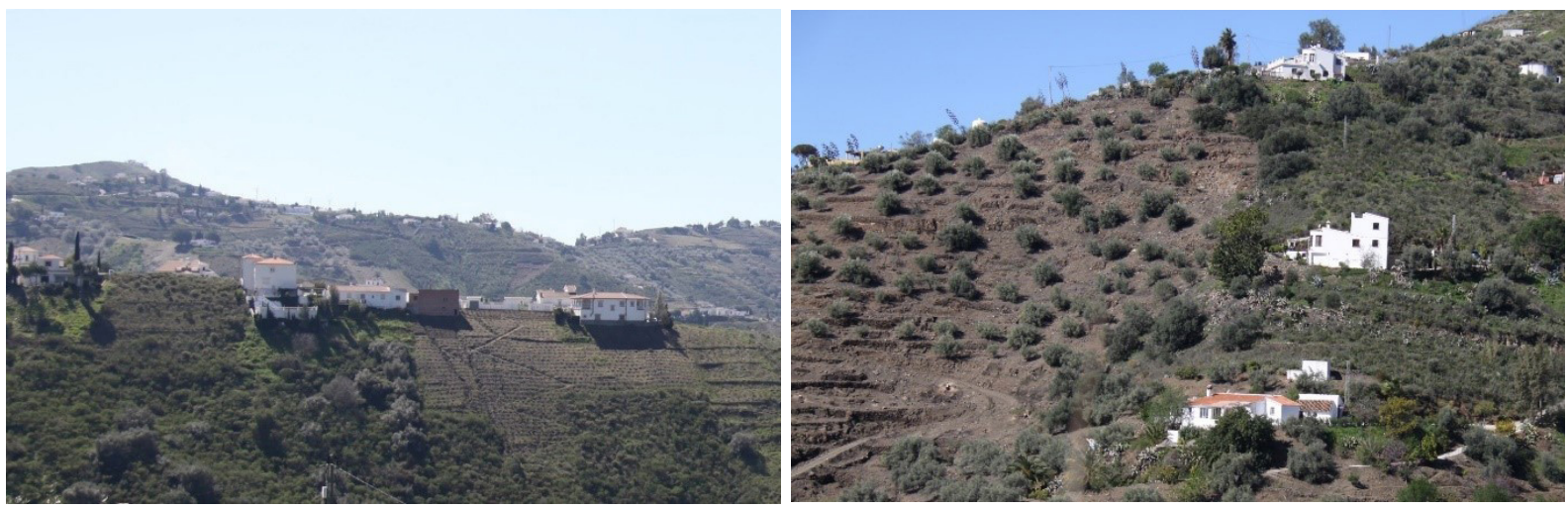

Fotografías de los autores 
Figura 17. Valoraciones sobre tipología de emplazamientos ( $\mathrm{A}=$ cumbres; $\mathrm{B}=$ laderas)

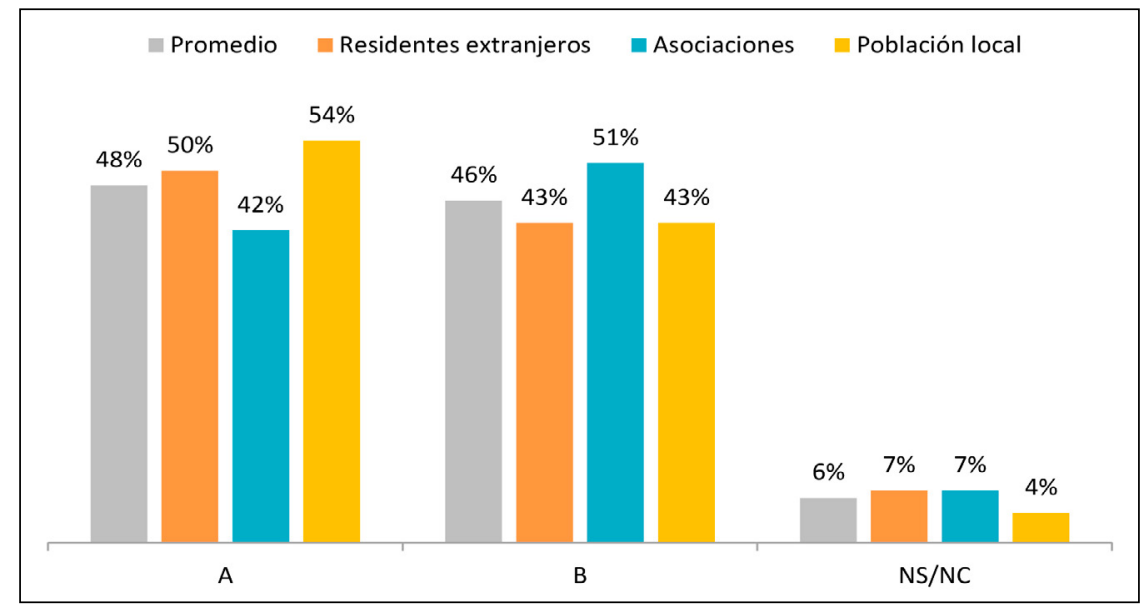

Elaboración propia

\subsubsection{Preferencias sobre tipologías arquitectónicas}

En una escala de aproximación más próxima, la tipología de la construcción puede suponer un factor de incidencia paisajística muy potente, por lo que se incluyó en la encuesta a través de la evaluación de diversos pares de fotografías que reflejaran los modelos tipológicos más habituales, sin denominarlos (ver ejemplo en Figura 18). En este sentido, unas líneas preferenciales sobre tipologías aparecen en las respuestas de forma más contundente que otras. En general, se rechaza tanto los estilos importados (como las construcciones prefabricadas de madera, en forma de cabaña alpina), como la arquitectura de estilo más puramente contemporáneo, incluso en casos que se podrían considerar como diseños de calidad bien resueltos paisajísticamente. En estos casos, los porcentajes de elección se sitúan entre el 16 y el 18\% en los residentes extranjeros y la población local, estando más equilibrado entre los miembros de asociaciones (56\%). Por el contrario, se apuesta claramente por los estilos tradicionales, algo que entra dentro de una cierta lógica conservadora, o por los que podrían denominarse como estilos híbridos o neotradicionales, el denominado modelo chalé: viviendas unifamiliares estructuralmente modernas pero que incluyen ciertos elementos que remiten a la arquitectura tradicional. En los resultados generales (Figura 19) hay una clara preferencia hacia estos últimos ( $58 \%$ frente a $42 \%$ ), pero existen grandes discrepancias entre los diferentes grupos de encuestados. Por ejemplo, entre los miembros de las asociaciones, el resultado se invierte claramente, decantándose muy contundentemente por las tipologías tradicionales (74\%). En cambio, entre los extranjeros hay una mayor preferencia por las tipologías híbridas, al igual que entre la población local, con porcentajes prácticamente opuestos a los obtenidos entre las asociaciones: un $73 \%$ eligen las híbridas y sólo un $27 \%$ las tradicionales. Entre las razones que subyacen en esta elección se encuentra, además de las razones antes expuestas (mayor conciencia patrimonial entre las asociaciones), la probable vinculación del modelo tradicional con construcciones viejas, con una cierta connotación de deterioro por su edad, mientras que los modelos híbridos son percibidos en mayor medida como nuevos, y por tanto mejor conservados, aunque sin dejar de mantener un cierto poso tradicional en su estilo arquitectónico.

Figura 18. Ejemplo de par fotográfico para preferencias sobre tipologías (modelo híbrido o chalé / tipologías contemporáneas)
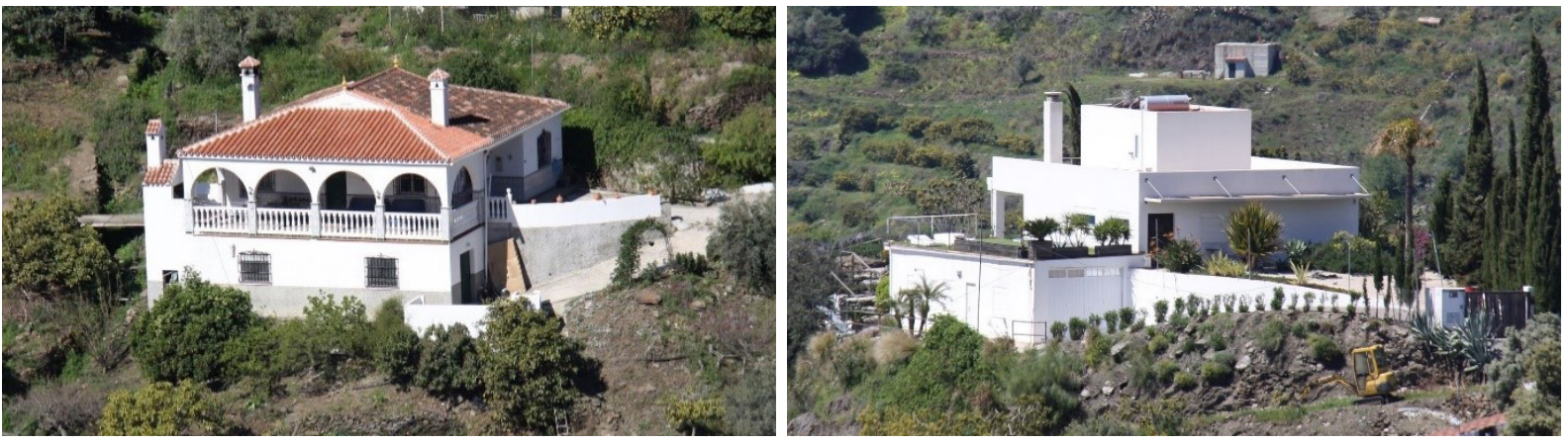

Fotografías de los autores 
Figura 19. Preferencias acerca del estilo arquitectónico de las viviendas ( $\mathrm{A}=$ tipologías híbridas o modelo chalé. $\mathrm{B}=$ tipologías tradicionales)

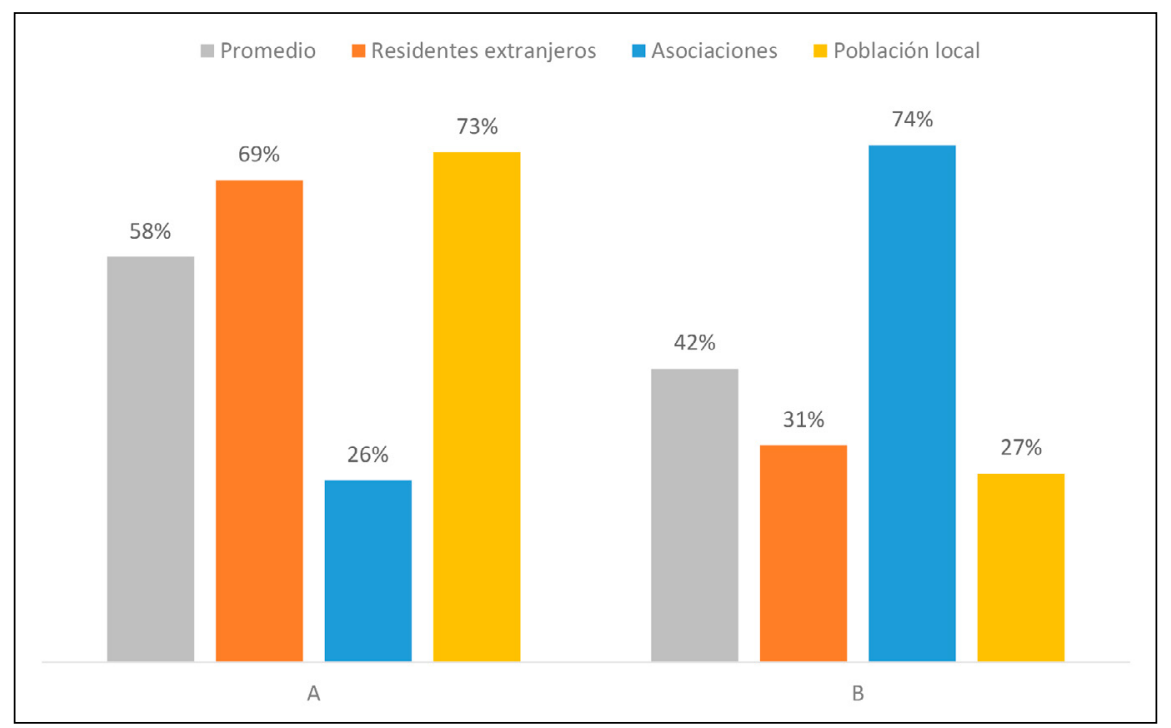

Elaboración propia

\subsubsection{Valoraciones sobre la ocupación del suelo en los espacios intersticiales}

El efecto paisajístico de las edificaciones dispersas trasciende a la propia edificación y a menudo afecta a los usos del suelo existentes entre ellas, los denominados espacios intersticiales; al mismo tiempo, el posible impacto paisajístico puede aminorarse, mejorando su integración, poniendo el acento no ya en las edificaciones, sino en estos espacios, no sólo por la mitigación del impacto visual, sino por el enriquecimiento del paisaje que puede suponer su adecuado tratamiento.

Figura 20. Opiniones sobre espacios intersticiales ( $\mathrm{A}=$ cultivos subtropicales; $\mathrm{B}=$ olivar)

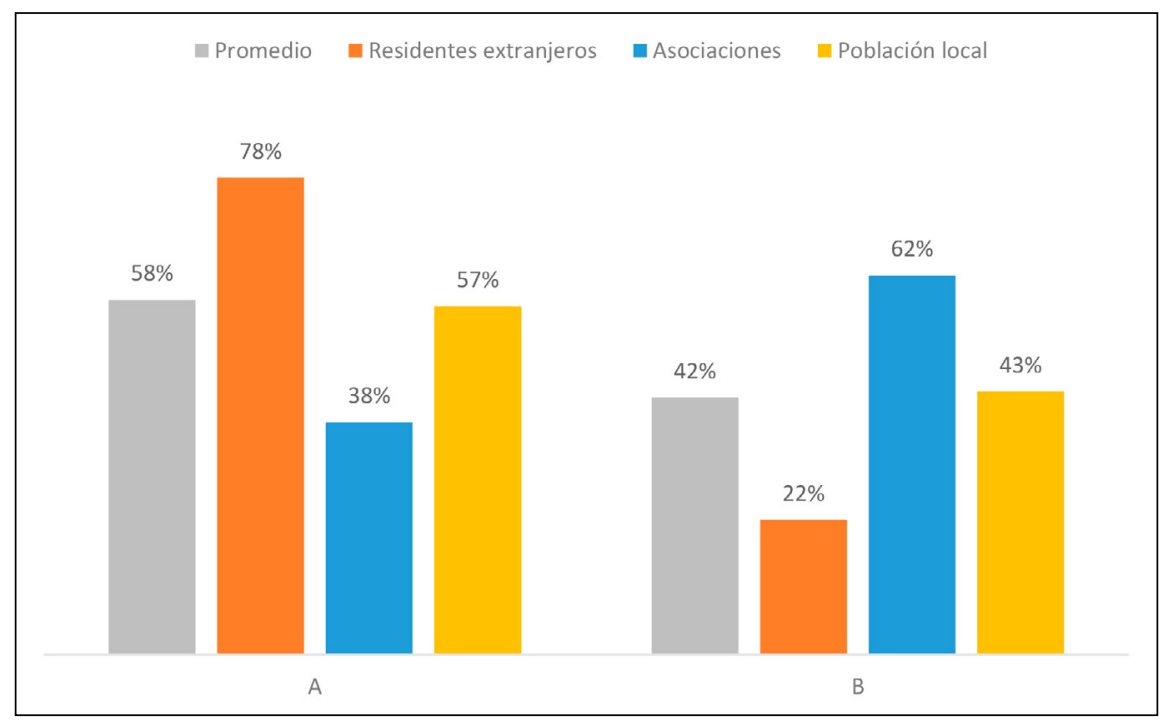

Elaboración propia

En los resultados, hay una marcada preferencia por la ocupación agraria del suelo, sobre todo arbórea, bien con cultivos subtropicales o bien con especies más tradicionales, como los olivos. No obstante, existen claras diferencias entre los grupos. Mientras que los extranjeros apuestan claramente por la frondosidad de los subtropicales, los encuestados de las asociaciones manifiestan una mayor preferencia por el más tradicional olivar; la población local se sitúa cerca de la media, ligeramente más atraída por los subtropicales, aunque con una sólida preferencia también por los tradicionales (Figura 20). Respecto 
al resto de usos del suelo, existe un claro rechazo de los invernaderos y de los espacios no agrarios sin cobertera arbórea, estando esta percepción negativa mucho más acusada entre los residentes extranjeros. Por ejemplo, las imágenes con invernaderos sólo son escogidas por el 3\% de los extranjeros, mientras entre la población local ese porcentaje llega el 30\%, reflejando claramente la percepción positiva de su productividad económica. Por su parte, los montes cubiertos de vegetación natural arbustiva reciben una mejor valoración por los encuestados de las asociaciones (que posiblemente valoren su naturalidad) y peor por parte de la población extranjera, que tiende a identificarlos como degradados al no contar con una gran presencia arbórea.

\subsection{Percepción sobre el futuro del paisaje de la comarca}

Finalizando el cuestionario, se sondeaba a los encuestados por su percepción del futuro del paisaje en la Axarquía. A pesar de los cambios territoriales que viene experimentando la comarca, algunos de ellos intensos, la mayoría de los encuestados se declara optimista, un $71 \%$, mientras que el $29 \%$ restante lo percibe de manera pesimista. De nuevo emergen diferencias entre los diferentes grupos, no radicalmente, pero sí de forma sustancial. Por ejemplo, entre los miembros de las asociaciones y los residentes extranjeros las diferencias se estrechan: $62,5 \%$ de respuestas optimistas en el primer caso y $58 \%$ en el segundo. Resulta interesante el porcentaje de percepciones pesimistas entre los propietarios extranjeros (42\%) y posiblemente en ellas influya la situación de inseguridad jurídica en la que se encuentran, aunque también puede reflejar la percepción de progresiva pérdida del paraíso rural que encontraron a su llegada. Por el contrario, entre la población local el porcentaje de respuestas positivas se eleva espectacularmente: un $89 \%$ de la población contempla con optimismo el futuro paisajístico de la comarca. Si se une este dato a los anteriores, se puede deducir que se trata de una población que en cierta medida valora las transformaciones que se están experimentando como un enriquecimiento del paisaje (Figura 21).

Figura 21. Percepción sobre el futuro del paisaje en la comarca

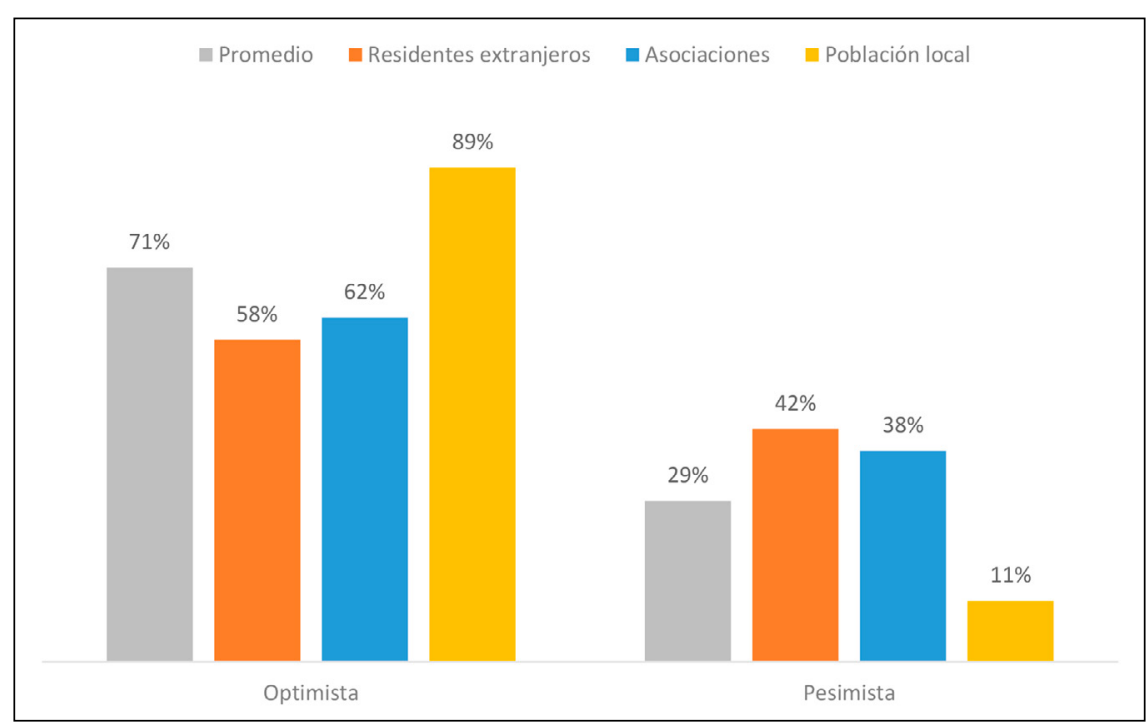

Elaboración propia

\section{Discusión de resultados}

El trabajo realizado aporta información y conclusiones útiles para la comprensión del fenómeno de la urbanización dispersa sobres suelos rurales, especialmente en su dimensión paisajística, así como para el diseño de posibles medidas de recuperación paisajística o, más genéricamente, de ordenación territorial. Se considera que el análisis de la percepción social constituye una herramienta imprescindible para abordar posibles soluciones al conflicto territorial y paisajístico generado. En la literatura existente se alude a la dimensión social del fenómeno, y en particular a las causas que motivan el desarrollo del urbanismo disperso en los entornos litorales mediterráneos, haciendo referencia entre ellos al atractivo paisajístico de estos espacios rurales; sin embargo, este acercamiento apenas se ha traducido en la realización de 
estudios específicos de percepción social. En este sentido, este trabajo puede ser contemplado como una primera aproximación a esta temática. No obstante, serían necesarios estudios adicionales para ratificar o matizar los resultados obtenidos, dado que los resultados que se ofrecen, obtenidos en el marco de un proyecto de investigación, no permite, por su propia magnitud económica, la realización de encuestas a gran escala, mucho menos a población aislada. Las dificultades en la organización de grupos, así como la propia naturaleza de algunos de esos grupos (como los residentes extranjeros en viviendas dispersas) ha impedido la realización de un mayor número de encuestas, aunque se considera que la cantidad realizada es razonable y que ha permitido obtener resultados de interés. Igualmente, sería aconsejable que la extensión de la encuesta alcanzara a otros grupos de población, como por ejemplo la población joven, a los que por motivos organizativos ha resultado difícil acceder de forma colectiva. Por otro lado, resulta de interés complementar los datos aportados por las encuestas a distintos grupos de población con la información obtenida a través de la aplicación de otra herramienta de percepción social, la entrevista a actores sociales cualificados. En este sentido, el proyecto en el que se enmarca este trabajo incluyó también la realización de entrevistas cualitativas a diferentes y numerosos actores sociales de la comarca, encontrándose en la actualidad en proceso de análisis e interpretación.

Por su parte, la zona de estudio analizada es altamente representativa, quizá incluso paradigmática, de este fenómeno, por lo que los resultados obtenidos trascienden al territorio seleccionado; aun así, sería necesario contrastar los resultados con los obtenidos en estudios similares que se realicen en otras áreas de estudio, especialmente de la zona sublitoral mediterránea, como por ejemplo la Comunidad Valenciana. Existen diversos y valiosos estudios relativos a variados aspectos de esta temática, que han analizado la expansión física de este tipo de sprawl, sus causas y consecuencias, siendo menos tratada la percepción social del fenómeno y más concretamente en relación a sus impactos paisajísticos. Más allá del área mediterránea, la extensión de un estudio de estas características a otras modalidades de poblamiento disperso, como pueda ser el sprawl urbano, como ocurre por ejemplo en determinados espacios periurbanos, posiblemente se enfrente a una problemática diferente, alejada de la existente en estas zonas rurales, más allá, por supuesto, de problemas comunes, como los relacionados con la legalidad urbanística o con la dotación de servicios.

\section{Conclusiones}

Como conclusión general, se puede deducir de los resultados obtenidos que existe una visión de la dimensión paisajística de la urbanización dispersa que no refleja la imagen del problema que normalmente transmiten los responsables políticos, los técnicos, los medios de comunicación e incluso el mundo académico. Los impactos en el paisaje son evidentes y se derivan de diversas variables (Mérida y Perles, 2020): elevada densidad de edificaciones, emplazamientos inadecuados, volumetrías excesivas, tipologías constructivas inapropiadas, escasa integración de elementos auxiliares (viales, vallados, muros de contención, etc.). Estos impactos se producen, además, sobre espacios rurales en los que, paradójicamente, el paisaje supone (y supuso), además de un recurso económico, un activo para la oferta inmobiliaria. Por ello, una política de ordenación territorial debe tener como objetivo detener este proceso y, especialmente, establecer medidas para la recuperación paisajística de estas áreas, entendiendo que la transformación del paisaje experimentada es, en la práctica, irreversible (salvo casos muy puntuales).

Sin embargo, el estudio muestra cómo existen importantes discrepancias entre los distintos grupos de encuestados sobre la base del problema, la percepción del impacto paisajístico y su relevancia. Esta conclusión obliga, por un lado, a la necesidad de explicar la naturaleza del impacto, de hacer pedagogía sobre el valor de lo público (el paisaje) respecto a lo privado (la vivienda), y sobre el sentimiento de propiedad sobre el paisaje, y por otro lado sugiere la conveniencia de revisar ideas quizá demasiado maximalistas que se han instalado en la percepción de los ciudadanos de las zonas urbanas sobre este problema. Se ha constatado que existe en una parte de los encuestados una visión más amable de la edificación dispersa, a menudo desarrollada sobre terrenos agrícolas abandonados, y esto implica, en su percepción, valorar un paisaje actual, que más allá de su atractivo concreto, constituye un paisaje vivo respecto a lo que probablemente sea percibido como restos de paisajes anteriores. Por otra parte, esta valoración, considerablemente extendida, posiblemente guarda una conexión semántica con un arraigado sentido de la propiedad en este espacio rural de tradición minifundista, que se traduce en un paisaje compartimentado, también en el proceso urbanizador. 
Por otro lado, se ha comprobado que existe mucha disparidad entre diversos grupos de población, especialmente entre los dos grupos de residentes locales y los miembros de asociaciones. En numerosos ítems se produce la paradoja de que la población extranjera, los propietarios de buena parte de estas edificaciones, suponen el colectivo que más se acerca, en líneas generales, a los valores medios del conjunto de la encuesta, cuando normalmente cabría pensar que fueran los que tuvieran una posición más extrema, debido a su clara implicación personal en este proceso territorial. La disparidad se manifiesta principalmente entre la población española, entre los miembros de las asociaciones, normalmente con un mayor nivel educativo y más comprometidos socialmente, y la población local residente en pequeños núcleos. Esta disparidad, que permitiría sospechar que pueda tener un trasfondo de naturaleza formativa o social, contiene también una clara correspondencia espacial, que contrapondría los espacios urbanos litorales, en líneas generales más conservacionistas, a los núcleos rurales interiores, de mentalidad más productivista.

Resulta útil, en todo caso, conocer esta realidad para poder diseñar y afrontar con éxito posibles y necesarias medidas de recuperación paisajística de las zonas afectadas por este fenómeno, algo que se recoge en las sucesivas normativas específicas de regularización urbanística de este fenómeno, en su correspondiente Plan de Ordenación Subregional (Junta de Andalucía, 2006) e incluso en la nueva legislación urbanística de Andalucía, en estos momentos en tramitación (Ley de impulso para la Sostenibilidad del Territorio de Andalucía). Para ello es prácticamente imprescindible contar con la participación de la población implicada, directa (propietarios) o indirectamente. En cualquier caso, una política de gobernanza territorial eficiente debe contemplar la participación de la población, como establece, en materia de paisaje, el Convenio Europeo del Paisaje. El conocimiento de la percepción social del problema, en este caso en su dimensión paisajística, puede constituir un punto de partida para la formulación de medidas que avancen en la recuperación paisajística de estos espacios.

\section{Financiación}

Este trabajo se enmarca en el proyecto de investigación denominado: 'Percepción social de la urbanización dispersa en entornos litorales mediterráneos y aplicación a la formulación de objetivo de calidad paisajística' financiado por el Ministerio de Economía y Competitividad (Proyectos de Excelencia. Código: CSO2015-67659-P).

\section{Referencias}

Barke, M. (1991). The growth and changing patter of recreational homes in Spain in the 1970s. Scottish Geographical Magazine, 107(1), 12-21. https://doi.org/10.1080/00369229118736802

Beriatos, E. (2008). Uncontrolled Urbanization, Tourism Development and Landscape Transformation in Greece. Congress Report, 44th ISOCARP Congress, Dalian (China). Recuperado de http://www. isocarp.net/Data/case_studies/1213.pdf

Burriel, E. (2009). La Unión Europea y el urbanismo valenciano. ¿Conflicto jurídico o político?”. Boletín Asociación de Geógrafos Españoles, 49, 5-23.

Burriel, E. (2018). Las viviendas secundarias ilegales de la etapa del desarrollismo. El ejemplo de Gilet (Valencia). Cuadernos de Geografía, 100, 23-58.

Council of Europe (2000). European Landscape Convention. Council of Europe Publications.

Couch, C., Leontidou L. y Petschel-Held, G. (2007). Urban sprawl in Europe: landscapes, land-use change E policy. https://doi.org/10.1002/9780470692066

Díaz Pacheco, J. y García Palomares, J.C. (2014). Urban sprawl in the mediterranean urban regions in Europe and the crisis effect on the urban land development: Madrid as Study Case. Urban Studies Research, article ID 807381. http://dx.doi.org/10.1155/2014/807381

European Environment Agency (EEA) (2006). Urban sprawl in Europe: The ignored challenge. Copenhagen: European Environment Agency.

European Environment Agency (EEA) \& Swiss Federal Office for the Environment (FOEN) (2016). Urban Sprawl in Europe. Luxembourg: European Environment Agency, Report 11/2016. 
Egidi, G., Cividino, S., Vinci, S., Sateriano, A. y Salvia, R. (2020). Towards local forms of sprawl: a brief reflection on Mediterranean urbanization. Sustainability, 12(2), 582. https://doi.org/10.3390/ $\underline{\text { sul2020582 }}$

ESRI (2021). Mapa Base Topográfico.

Ezquiaga, J.M. (1983). Parcelaciones ilegales en suelo no urbanizable: nuevas formas de consume del espacio en los márgenes de la ley del suelo. Ciudad y Territorio, 56, 59-72.

Gonzalez-Abraham, C.E., Radeloff, V.C., Hammer, R.B., Hawbaker, T.J., Stewart, S.I. y Clayton, M.K. (2007). Building Patterns and Landscape Fragmentation in Northern Wisconsin, USA. Landscape Ecology, 22(2), 217-230. https://doi.org/10.1007/s10980-006-9016-z

Hall, M. y Müller, D. (Eds.) (2004). Tourism, mobility and second homes. Between elite landscape and common ground. https://doi.org/10.21832/9781873150825

Hof, A. y Blázquez-Salom, M. (2013). The Linkages between Real Estate Tourism and Urban Sprawl in Majorca (Balearic Islands, Spain). Land, 2, 252-277. https://doi.org/10.3390/land2020252

Hortas-Rico, M. y Solé-Ollé, A. (2010). Does urban sprawl increase the costs of providing local public services? Evidence from Spanish municipalities. Urban Studies, 47(7), 1513-1540. https://doi. org/10.1177/0042098009353620

Inostroza, L., Baur, R. y Csaplovics, E. (2013). Urban sprawl and fragmentation in Latin America: A dynamic quantification and characterization of spatial patterns. Journal of environmental management, 115, 87-97. https://doi.org/10.1016/j.jenvman.2012.11.007

Instituto de Estadística y Cartografía de Andalucía (2020). Sistema de Información Multiterritorial de Andalucía (SIMA). Consejería de Transformación Económica, Industria, Conocimiento y Universidades. Junta de Andalucía.

Instituto de Estadística y Cartografía de Andalucía (2019). Datos Espaciales de Referencia de Andalucía (DERA): Limites Administrativos. Consejería de Transformación Económica, Industria, Conocimiento y Universidades. Junta de Andalucía.

Instituto Geográfico Nacional (2019). Plan Nacional de Ortofotografía Aérea (PNOA). Ministerio de Transporte Movilidad y Agenda Urbana. Gobierno de España.

Instituto Nacional de Estadística (INE) (2019). Revisión Padrón Municipal.

James, P., Troped, P. J., Hart, J. E., Joshu, C. E., Colditz, G. A., Brownson, R. C. y Laden, F. (2013). Urban sprawl, physical activity, and body mass index: nurses' health study and nurses' health study II. American journal of public health, 103(2), 369-375. https://doi.org/10.2105/AJPH.2011.300449

Junta de Andalucía (2018). Red de Información Ambiental de Andalucía (REDIAM), 2018.

Junta de Andalucía (2006). Plan de Ordenación del Territorio Costa del Sol Oriental - Axarquía. Consejería de Obras Públicas y Transportes.

Justicia, A. (1988). La Axarquía malagueña y la costa oriental. Dos espacios agrarios contrapuestos. Málaga: editorial Arguval.

Leontidou, L. y Marmaras, E. (2001). From tourist to migrants: residencial tourism and 'littoralization'. En Y. Apostolopoulos, P. Loukissas y L. Leontidou (Eds.), Mediterranean tourism: Facets of socioeconomic development and cultural change (pp. 257-267). London: Routledge.

Mann, S. (2009). Institutional causes of urban and rural sprawl in Switzerland. Land Use Policy, 26(4), 919-924. https://doi.org/10.1016/j.landusepol.2008.11.004

Mantecón, A., Membrado, J. C. y Huete, R. (2016). Fragmentación socio-espacial, inmigración europea y discursos políticos en la Provincia de Alicante. Boletín de la Asociación de Geógrafos Españoles, (72), 67-90.

Mazón, T. y Aledo, A. (2005). El dilema del turismo residencial: ¿turismo o desarrollo inmobiliario?. En T. Mazón y A. Aledo (Eds.), Turismo residencial y cambio social. Nuevas perspectivas teóricas y empíricas (pp. 13-29). Alicante: Editorial Aguaclara.

Meeus, S. y Gulinck, H. (2008). Semi-Urban Areas in Landscape Research: A Review. Living Review Landscape Research, 2. https://doi.org/10.12942//rlr-2008-3 
Membrado, J.C. (2013). Sunny Spain: migrantes del sol y urbanismo expansivo en el litoral mediterráneo español. Ciudad y Territorio. Estudios Territoriales, 45(178), 687-708.

Membrado, J. C. (2015). Migración residencial y urbanismo expansivo en el Mediterráneo español. Cuadernos de Turismo, (35), 259-286.

Mérida Rodríguez, M. y Perles Roselló, M.J. (2020). La integración paisajística como instrumento de gobernanza e inteligencia territorial y su aplicación a la urbanización dispersa. En Gómez Jiménez, M.L. (dir.), Inteligencia territorial y regulación económica (pp. 149-176). Pamplona: Thomson-Reuters Aranzadi.

Mérida Rodríguez, M. (2019). Paisaje, procesos territoriales, transformaciones paisajísticas y percepción social en la comarca de la Axarquía (Málaga). Erebea, (9), 105-132. https://doi.org/10.33776/erebea. v9i0.3789

Módenes, J.A. y López, J. (2007). Recreational homes in Spain: Socio-demographic and geographical profiles. Population (English Edition), 62(1), 157-71. https://doi.org/10.3917/pope.701.0157

Morote, A.F. y Hernández, M. (2016a). Población extranjera y turismo residencial en el litoral de Alicante (1960-2010): repercusiones territoriales. Eure, 42(116), 55-76. https://doi.org/10.4067/S0250$\underline{71612016000200003}$

Morote, A.F. y Hernández, M. (2016b). Urban sprawl and its effects on water demand: A case study of Alicante. Spain. Land Use Policy, 50, 252-362. https://doi.org/10.1016/j.landusepol.2015.06.032

Morris, D. E. (2013). It's a Sprawl World After All: The human cost of unplanned growth-and visions of a better future. New Society Publishers.

Oueslati, W., Alvanides, S. y Garrod, G. (2015). Determinants of urban sprawl in European cities. Urban Studies, 52(9), 1594-1614. https://doi.org/10.1177/0042098015577773

Salvati, L. y Gargiulo, V. (2014). Unveiling urban sprawl in the mediterranean region: Towards a latent urban transformation?. International Journal of Urban and Regional Research, 38(6), 1935-1953.

Yue, W., Liu, Y. y Fan, P. (2013). Measuring urban sprawl and its drivers in large Chinese cities: The case of Hangzhou. Land use policy, 31, 358-370. https://doi.org/10.1016/j.landusepol.2012.07.018

Yus, R. y Torres Delgado, M.A. (2010). Urbanismo difuso en suelo rústico. Málaga: GENA-Ecologistas en Acción.

\section{Referencias legales:}

Decreto 2/2012, de 10 de enero, por el que se regula el régimen de las edificaciones y asentamientos existentes en suelo no urbanizable en la Comunidad Autónoma de Andalucía.

Ley 6/2016, de 1 de agosto, por la que se modifica la Ley 7/2002, de 17 de diciembre, de Ordenación Urbanística de Andalucía para incorporar medidas urgentes en relación con las edificaciones construidas sobre parcelaciones urbanísticas en suelo no urbanizable.

Ley 2/2018, de 26 de abril, relativa a modificación de la Ley 6/2016, de 1 de agosto, por la que se modifica la Ley 7/2002, de 17 de diciembre, de Ordenación Urbanística de Andalucía, para incorporar medidas urgentes en relación con las edificaciones construidas sobre parcelaciones urbanísticas en suelo no urbanizable. 